\title{
FRED-QD: A Quarterly Database for Macroeconomic Research
}

\author{
Michael W. McCracken and Serena $\mathrm{Ng}$
}

In this article, we present and describe FRED-QD, a large, quarterly frequency macroeconomic database that is currently available and regularly updated at https://research.stlouisfed.org/econ/ mccracken/fred-databases/. The data provided are closely modeled to that used in Stock and Watson (2012a). As in our previous work on FRED-MD (McCracken and Ng, 2016), which is at monthly frequency, our goal is simply to provide a publicly available source of macroeconomic "big data" that is updated in real time using the FRED ${ }^{\circledR}$ data service. We show that factors extracted from the FRED-QD dataset exhibit similar behavior to those extracted from the original Stock and Watson dataset. The dominant factors are shown to be insensitive to outliers, but outliers do affect the relative influence of the series, as indicated by leverage scores. We then investigate the role unit root tests play in the choice of transformation codes, with an emphasis on identifying instances in which the unit root-based codes differ from those already used in the literature. Finally, we show that factors extracted from our dataset are useful for forecasting a range of macroeconomic series and that the choice of transformation codes can contribute substantially to the accuracy of these forecasts. (JEL C30, C33, C82)

Federal Reserve Bank of St. Louis Review, First Quarter 2021, 103(1), pp. 1-44. https://doi.org/10.20955/r.103.1-44

\section{INTRODUCTION}

In our previous work, McCracken and $\mathrm{Ng}$ (2016), we describe and investigate a monthly frequency database of macroeconomic variables called FRED-MD. At some level, FRED-MD is not particularly innovative. It is, after all, just a collection of $N=128$ standard U.S. macroeconomic time series that date back to January 1959 and have primarily been taken from FRED $^{\oplus}$, the data service maintained by the Federal Reserve Bank of St. Louis, and organized into a .csv file. That description, however, misses the point. Our main goal was to facilitate easy access to a standardized example of a data-rich environment that can be used for academic

\footnotetext{
Michael W. McCracken is an assistant vice president and economist at the Federal Reserve Bank of St. Louis. Serena Ng is the Edwin W. Rickert Professor of Economics at the Department of Economics and Data Science Institute at Columbia University and a research associate at the National Bureau of Economic Research. Financial support to Serena Ng is provided by the National Science Foundation (SES 1558623). The authors thank Aaron Amburgey and Joe McGillicuddy for excellent research assistance and especially thank Yvetta Fortova for being the FRED ${ }^{\circledR}$ insider who operationalized this project.

( ) 2021, Federal Reserve Bank of St. Louis. The views expressed in this article are those of the author(s) and do not necessarily reflect the views of the Federal Reserve System, the Board of Governors, or the regional Federal Reserve Banks. Articles may be reprinted, reproduced, published, distributed, displayed, and transmitted in their entirety if copyright notice, author name(s), and full citation are included. Abstracts, synopses, and other derivative works may be made only with prior written permission of the Federal Reserve Bank of St. Louis.
} 


\section{McCracken and $\mathbf{~ g g}$}

research. By automating this dataset, and maintaining a website that provides monthly frequency vintages, those who are interested in conducting research on big data can focus on the statistical problems associated with big data rather than having to put the dataset together themselves. This dataset frees the practitioner from dealing with issues related to, for example, updating the dataset when new data is released, managing series that become discontinued, and splicing series from different sources. More prosaically, FRED-MD facilitates comparison of methodologies developed for a common purpose.

FRED-MD has been successful. It has been used as a foil for applying big data methods including random subspace methods (Boot and Nibbering, 2019), sufficient dimension reduction (Barbarino and Bura, 2017), dynamic factor models (Stock and Watson, 2016), large Bayesian VARs (Giannone, Lenza, and Primiceri, 2018), various lasso-type regressions (Smeekes and Wijler, 2018), functional principal components, (Hu and Park, 2017), complete subset regression (Kotchoni, Leroux, and Stevanovich, 2019), and random forests (Medeiros et al., 2019). In addition, these various methods have been used to study a wide variety of economic and financial topics including bond risk premia (Bauer and Hamilton, 2017), the presence of real and financial tail risk (Nicolò and Lucchetta, 2016), liquidity shocks (Ellington, Florackis, and Milas, 2017), recession forecasting (Davig and Hall, 2019), identification of uncertainty shocks (Angelini et al., 2019), and identification of monetary policy shocks (Miranda-Agrippino and Ricco, 2017). Finally, and perhaps most rewarding, is that it is described as the inspiration to the development of a Canadian version of FRED-MD (Fortin-Gagnon et al., 2018).

While useful, FRED-MD has a glaring weakness. It does not include quarterly frequency data and thus does not provide information on gross domestic product (GDP), consumption, investment, government spending, or other macroeconomic series that come from the National Income and Product Accounts (NIPA). This is unfortunate because there are plenty of examples in the literature in which a quarterly frequency, data-rich environment is used for economic analysis. Examples include Stock and Watson (2012a,b), Schumacher and Breitung (2008), Gefang, Koop, and Poon (2019), Rossi and Sekhposyan (2015), Gonçalves, Perron, and Djogbenou (2017), Carrasco and Rossi (2016), Koopman and Mesters (2017), and Koop (2013).

In this article, we extend our previous work to a quarterly frequency dataset we call FRED-QD. The dataset is currently available at https://research.stlouisfed.org/econ/ mccracken/fred-databases/. Like FRED-MD, FRED-QD is benchmarked to previous work by Stock and Watson (2012a, hereafter S\&W). There, the authors organized a collection of $N=200$ quarterly frequency macroeconomic series dating back to 1959:Q1 that they then used to analyze the dynamics of the Great Recession. Our quarterly frequency version of their dataset contains nearly all the series they used but, in addition, includes 48 more series, with an emphasis on including series related to non-household balance sheets. In total, the dataset consists of $N=248$ quarterly frequency series dating back to 1959:Q1. 1 While many of the series are actually quarterly series, some are higher-frequency series that have been aggregated up to the quarterly frequency - typically as quarterly averages of monthly series.

It's worth noting that we provide the data in levels-without transforming them in any way. As such, some are stationary in levels, while others likely need to be transformed by taking 
logs, differencing, or both to reasonably be considered stationary. For each series we provide benchmark transformation codes. If the series was in the S\&W dataset, we provide the transformation codes. For the additional series, many are taken from FRED-MD and we therefore provide those benchmark transformation codes. One reason to do this is to facilitate replication of the factor analysis provided in S\&W as well as other results that may have used a similar dataset. Even so, given the well-documented changes in volatility and persistence of macroeconomic series described in Campbell (2007) and Stock and Watson (2007), it may be a good idea to reconsider the default transformation codes. After providing more details on the data, we investigate this possibility through the lens of unit root tests. While it is often the case that the unit root tests align with the original transformation codes, the tests are not uniformly supportive.

We then investigate whether factors extracted from FRED-QD are useful for forecasting macroeconomic aggregates. In particular, we focus on whether the unit root-implied transformation codes matter for factor-based forecasting. $\stackrel{2}{ }$ Among the series that we forecast, we find that for real and financial series, factors estimated using the unit root-based transformation codes can provide additional predictive content but are more often dominated by those using the original transformation codes. In contrast, we find that when forecasting nominal price series, forecast accuracy is typically better when using factors estimated using the unit root-based codes. This result coincides with evidence provided by Medeiros et al. (2019) and Goulet Coulombe et al. (2019), who find that treating price inflation as I(0) leads to better forecasts of inflation than treating it as I(1) - which is precisely what the benchmark transformation codes recommend.

The remainder of the article proceeds as follows. Section 2 provides a more detailed description of the series in FRED-QD as well as choices that were made when putting them together. Section 3 presents a brief analysis of the behavior of factors extracted from our dataset, with an emphasis on their relationship with factors extracted from the original S\&W dataset. Section 4 constructs statistical leverage scores as a means of identifying which series and data points have the greatest influence on the factors. Section 5 provides a detailed investigation of the degree to which unit root tests agree with the benchmark transformation codes. Section 6 investigates the degree to which factors are useful for forecasting, with particular attention to whether the unit root determined transformation codes improve the accuracy of the forecasts relative to the original codes. Section 7 concludes. A detailed list of the series is provided in the appendix.

\section{FRED-QD}

As with FRED-MD, the goal of FRED-QD is to provide a readily accessible, easy-to-use macroeconomic database that can form the basis of research on big data. To do so, we make the dataset publicly available at the same website as FRED-MD so that anyone can have access. Importantly, a new vintage of the dataset is created on the last business day of each month. This means that at the end of each month, (i) the most recent data releases have been added, (ii) revisions to the series in previous quarters have been taken on board, and (iii) institutional 


\section{McCracken and $\mathbf{N g}$}

changes to existing series, periodically made by the statistical agencies, have been appropriately accounted for (e.g., a substitute series is found for a discontinued series).

Based on feedback we received for the FRED-MD project, the most recent vintage is always given a hotlink denoted "current." This allows the user to include that link within their code and thus always have access to the most recent vintage without having to go to the website manually and download the file. Previous vintages of the dataset are retained on the website. By retaining the older vintages, we facilitate replication of other research that has used FRED-QD. For example, if a researcher develops a new statistical method for working with big data and wants to compare their results with that from an existing paper, one can go back and find the exact vintage of FRED-QD used in that paper so that differences in results can be attributed to the method rather than the dataset.

On the website, we also provide a "Changes to FRED-QD" file that keeps a running tally of modifications that have occurred across the history of FRED-QD. For example, when creating the September 2018 vintage of FRED-QD, three non-household balance sheet series were discontinued and replaced with comparable series. This event, and the subsequent changes in mnemonics, was documented in the changes file. It's worth noting that changes can also arise due to issues not associated with statistical agencies. For example, legal issues regarding FRED $^{\infty}$ 's ability to post a given series, or to do so only with a substantial delay, sometimes arise. Examples of such are provided in the "Changes to FRED-MD" file, and one can expect similar issues to ultimately arise in FRED-QD.

With these issues in mind, FRED-QD consists of 248 quarterly series. A full list of the data is given in the appendix. FRED-QD seeks to keep roughly the same coverage as the S\&W dataset while allowing the experts at $\mathrm{FRED}^{\circ}$ to handle data revisions and definitional changes. The series are classified into 14 groups: NIPA; Industrial Production; Employment and Unemployment; Housing; Inventories, Orders, and Sales; Prices; Earnings and Productivity; Interest Rates; Money and Credit; Household Balance Sheets; Exchange Rates; Other; Stock Markets; and Non-Household Balance Sheets. These groups are similar to, but not the same as, those used in S\&W. The original groups included (i) Housing Starts, (ii) Housing Prices, and (iii) Stock Prices, Wealth, \& Household Balance Sheets, which we have rearranged to form the Housing, Household Balance Sheets, and Stock Markets groups. In addition, NonHousehold Balance Sheets is a completely new group. These series were added as a reaction to the Financial Crisis of 07-09, during which financial balance sheets played a large role in initiating the crisis and exacerbating the recovery. As such, they could be useful in applications in which FRED-QD is used for business cycle analysis.

Of the 248 series, 70 series were not trivially accessed from FRED ${ }^{\circledR}$ and needed some kind of massaging prior to being comparable to the corresponding series in S\&W. A large portion of those that needed massaging were simply a matter of making nominal series real using a deflator. For each of these series, this procedure is explained in the appendix. For the remaining modified series, a summary of the changes is provided in Table 1. For clarity, all series that required some form of modification are tagged with an " $x$ " to indicate that the variable has been adjusted and thus differs from the original series from the source. 


\section{Table 1}

\section{Series Adjusted by FRED-QD}

\begin{tabular}{|c|c|c|}
\hline Number & Variable & Adjustment \\
\hline 60 & Unemployment rate (<27 weeks) & (UNEMPLOY - UEMP27OV)/CLF16OV \\
\hline 61 & Unemployment rate (>27 weeks) & UEMP27OV/CLF16OV \\
\hline 80 & Help-wanted index & Splice LMJVTTUVUSM647S with Barnichon (2010) series \\
\hline 88 & Real manu. and trade & $\begin{array}{l}\text { (i) Adjust M0602BUSM144NNBR for inflation using PCEPI } \\
\text { (ii) Seasonal adjust with ARIMA X12 } \\
\text { (iii) Splice with NAICS series CMRMTSPL }\end{array}$ \\
\hline 89 & Retail/food sales & Splice SIC series RETAIL with NAICS series RSAFS \\
\hline 90 & New orders (durables) & Splice SIC series AMDMNO and NAICS series DGORDER \\
\hline 92 & Unfilled orders (durables) & Splice SIC series AMDMUO and NAICS series AMDMUO \\
\hline 93 & New orders (nondefense) & Splice SIC series ANDENO and NAICS series ANDENO \\
\hline 130 & Crude Oil & Splice OILPRICE with MCOILWTICO \\
\hline 153 & $30 \mathrm{yr}$ mortgage to $10 \mathrm{yr}$ Treasury & MRTG - GS10 \\
\hline 154 & 6mth T-bill - 3mth T-bill & TB6M - TB3M \\
\hline 155 & 1yr Treasury - 3mth T-bill & GS1 - TB3M \\
\hline 156 & 10yr Treasury - 3mth T-bill & GS10 - TB3M \\
\hline 157 & 3mth Commercial - 3mth T-bill & CPF3M - TB3M \\
\hline 172 & Household/Nonprof liab to income & TLBSHNO/PI \\
\hline 174 & Household/Nonprof networth to income & TNWBSHNO/PI \\
\hline 178 & S\&P 100 Volatility: VXO & Splice Bloom (2009) series with VXOCLS \\
\hline 184 & Switzerland/U.S. FX & Filled back to 1959 from Banking/Monetary statistics \\
\hline 185 & Japan/U.S. FX & Filled back to 1959 from Banking/Monetary statistics \\
\hline 186 & U.K./U.S.FX & Filled back to 1959 from Banking/Monetary statistics \\
\hline 187 & Cdn/U.S. FX & Filled back to 1959 from Banking/Monetary statistics \\
\hline 188 & Consumer sentiment & Splice UMSCENT1 with UMSCENT \\
\hline 220 & Help wanted to unemployed & HWI/UNEMPLOY \\
\hline 221 & Initial claims & Splice monthly series M08297USM548NNBR with weekly ICSA \\
\hline 222 & Business inventories & Splice SIC series and NAICS series BUSINV \\
\hline 223 & Inventory to sales & Splice SIC series and NAICS series ISRATIO \\
\hline 224 & Consumer credit to P.I. & NONREVSL/PI \\
\hline 235 & Business liabilities to income & TLBSNNCB/BDI \\
\hline 238 & Business net worth to income & TNWMVBSNNCB/BDI \\
\hline 240 & NonCorp busi. liabilities to income & TLBSNNB/BDI \\
\hline 243 & NonCorp busi. net worth to income & TNWBSNNB/BDI \\
\hline 244 & Business income & (CNCF - FCTAX)/IPDPS \\
\hline
\end{tabular}




\section{McCracken and $\mathbf{~ g g}$}

When producing each vintage of the dataset, an additional quarterly observation is added only after the first calendar month of the current quarter, which typically means once the first NIPA data, associated with the previous calendar quarter, are released. For example, the January, February, and March 2019 vintages of FRED-QD report quarterly data associated with 2018:Q4 but no data associated with 2019:Q1. The first vintage that contains any 2019:Q1 data is the April 2019 vintage. Within a calendar quarter, the existing quarterly values can be revised due to monthly frequency revisions of quarterly series such as GDP or monthly frequency series such as retail sales.

Due to data availability and the timing of data releases, FRED-QD is not a balanced panel. As we noted above, we introduce a new calendar quarter to the panel one month into the following quarter. In this vintage, any series that is released with more than a one-month lag is treated as missing (e.g., series associated with the Productivity and Costs release by the Bureau of Labor Statistics). In the following vintage, any series that is released with more than a twomonth lag is treated as missing (e.g., series associated with the Financial Accounts of the United States [Z.1] data release by the Board of Governors of the Federal Reserve System). In the final vintage for that calendar quarter, all series have typically been released and there are no missing

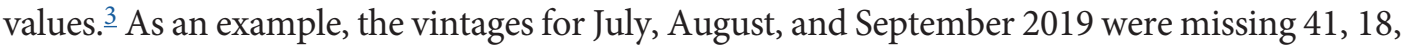
and 0 observations associated with 2019:Q2, respectively. Another, less-regular reason for missing observations arises during government shutdowns. For example, U.S. statistical agencies were closed from December 22, 2018, through January 25, 2019. Because this led to delays in the release of many series, the January 2019 vintage of FRED-QD, which typically would be missing 40 or so observations associated with 2018:Q4 data, is instead missing 87 observations.

All but 38 series are available starting in 1959:Q1. There are a variety of reasons for series to have missing observations at the beginning of the sample: (i) Some series, such as Housing Permits, simply didn't exist in 1959:Q1 and only became available in 1960:Q1. (ii) Similarly, the Michigan Survey of Consumer Sentiment is missing two observation at the beginning of the sample because the survey was not conducted on a regular basis until 1959:Q1. (iii) For other series such as the Trade-weighted Exchange Rate, the series is available in FRED ${ }^{\circledR}$ only through 1973:Q1 and we have not found other documented sources with which to splice the series. (iv) Finally, FRED ${ }^{\circledast}$ primarily holds North American Industry Classification System (NAICS) data (though some older Standard Industrial Classification [SIC] data exist and are used whenever possible) from the Census Manufacturers Survey, and hence a few Value of Manufacturers' Orders components like Nondefense Capital Goods and especially Consumer Goods have a limited history.

In many applications of big data, it is expected that the series are stationary. Since it is clear that not all of the series in FRED-QD are stationary in levels, we also provide benchmark transformation codes that are intended to transform the series so that they are stationary. In each instance, a decision is made to treat the series in levels or log levels, and then, based on whether that series is considered $I(0), I(1)$, or $I(2)$, the variable is differenced to the appropriate degree. For a given series $x$, these codes take the following forms: (i) no transformation; (ii) $\Delta x_{t}$; (iii) $\Delta^{2} x_{t}$; (iv) $\log \left(x_{t}\right)$; (v) $\Delta \log \left(x_{t}\right)$; (vi) $\Delta^{2} \log \left(x_{t}\right)$; and (vii) $\Delta\left(x_{t} / x_{t-1}-1.0\right.$ ). For most of the series, these codes are the original transformations used by $S \& W$. For series that we've 
added, many are monthly series taken from FRED-MD that we have aggregated to a quarterly frequency. For these series, we use the benchmark transformation codes reported in FRED-MD. Finally, we also provide an indicator that identifies those series in FRED-QD that were used by S\&W to estimate factors. This allows the user to focus on those series in the original S\&W dataset if the additional series in FRED-QD are deemed extraneous for a particular application.

\section{FACTOR ESTIMATES}

In this section, we provide an analysis of principal component analysis (PCA)-based factors extracted from FRED-QD. Principal components remain a simple way of transforming the information content in a large number of series into a smaller number of manageable series. Once the components have been extracted, they have been used for many purposes, including recession dating (Stock and Watson, 2016), forecasting (Boivin and Ng, 2005), measuring uncertainty (Jurado, Ludvigson, and Ng, 2015), and evaluating monetary policy (Bernanke and Boivin, 2003). Under certain assumptions, principal components provide consistent estimates of common factors and we will use the two terms interchangeably. We are mainly interested in differences in the data through the lens of PCA rather than the method itself.

Another motivation for analyzing the factors is that we have purposefully benchmarked FRED-QD to the large dataset of quarterly frequency series used by S\&W. In that paper, the authors extract PCA-based factors and use them to disentangle the causes of the Great Recession. Hence, as a means of verifying that we have adequately captured the information in their dataset, we also provide a direct comparison of factors extracted from FRED-QD to those extracted from the original dataset used by S\&W. 4 To do so, we use the September 2019 vintage of FRED-QD, but only those observations and series that were used to estimate factors in the original dataset. Keeping in mind that FRED-QD does not have 10 of the series in the original dataset, but provides a substitute for one of them, this ultimately gives us $T=211$ observations ranging from 1959:Q1 to 2011:Q3 and N=125 or 132 series when using FRED-QD or the original dataset, respectively.

Because FRED-QD has missing values and outliers that we treat as missing, ${ }^{5}$ we estimate the factors by PCA adapted to allow for missing values. Our approach to doing so is closely related to the EM (expectation-maximization) algorithm given in Stock and Watson (2002). Each series is demeaned and normalized to unit variance using the sample means and standard deviations, respectively. If the time $t=1, \ldots, T$ observation for series $i=1, \ldots, N$ is missing, we initialize it to the unconditional sample mean based on the non-missing values (which is zero since the data are demeaned and standardized) so that the panel is rebalanced. Based on this panel, and for a given number of factors $r$, a $T \times r$ matrix of factors $F=\left(f_{1}, \ldots, f_{T}\right)^{\prime}$ and a $N \times r$ matrix of loadings $\lambda=\left(\lambda_{1}, \ldots, \lambda_{N}\right)^{\prime}$ are estimated using the normalization that $\lambda^{\prime} \lambda / N=I_{r}$. We then update the missing values for each series from zero to $\hat{\lambda}_{i}^{\prime} \hat{f}_{t}$. This is multiplied by the standard deviation of the series and the mean is re-added. The resulting value is treated as an observation for series $i$ at time $t$, and the mean and variance of the complete sample are recalculated. The process of demeaning, standardizing, and estimating the factors and loadings is repeated using the updated panel. The iteration stops when the factor estimates do not change. $\underline{6}$ 


\section{McCracken and $\mathbf{~ g g}$}

Figure 1

FRED-QD and S\&W Factor Estimates

\section{A. Factor 1 Estimates}

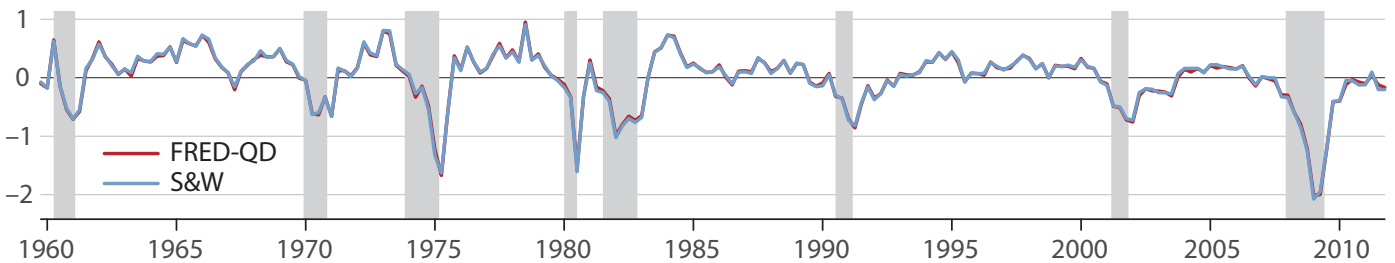

\section{B. Factor 2 Estimates}

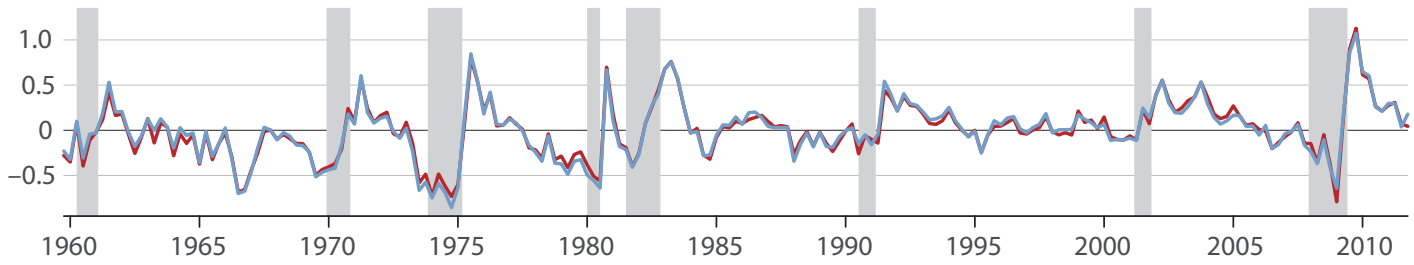

\section{Factor 3 Estimates}

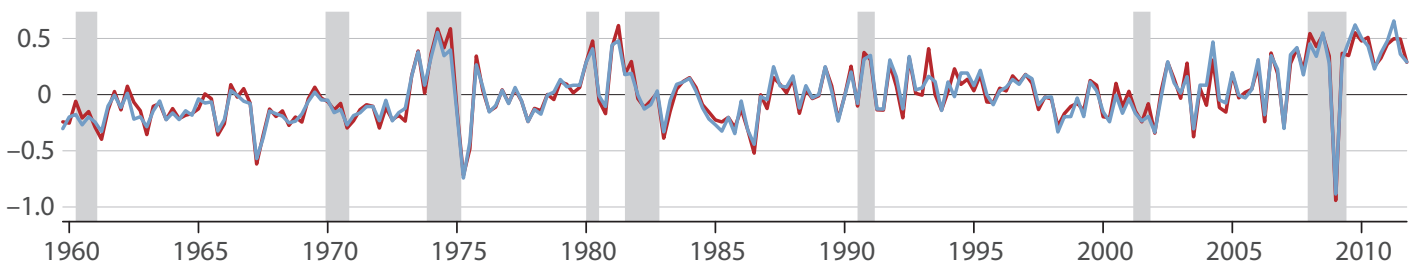

D. Factor 4 Estimates

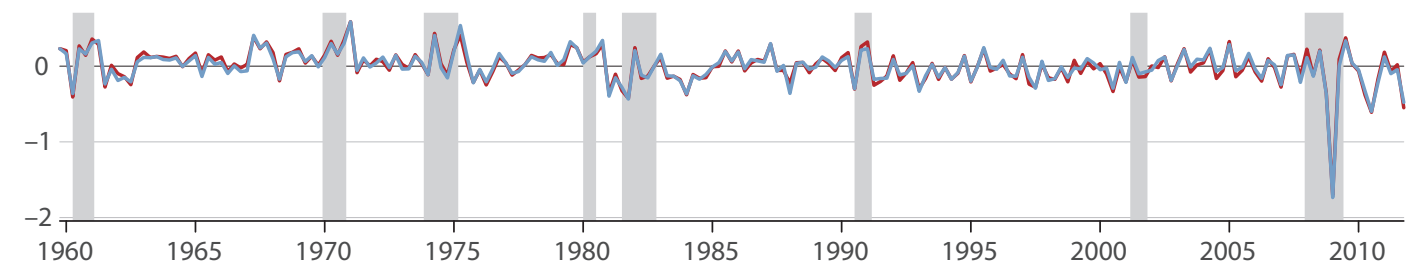

NOTE: This figure shows the estimates of Factors 1-4 for both the S\&W and FRED-QD datasets. For estimation of factors in the FRED-QD dataset, only series and observations that correspond to those in the S\&W dataset are used. Gray bars indicate recessions as determined by the NBER.

We then select the number of significant factors $r$. We use the $I C_{p}$ criteria developed in Bai and Ng (2002), which are generalizations of Mallow's $C_{p}$ criteria for large dimensional panels. The number of factors is chosen to minimize the sum of squared residuals while keeping the model parsimonious. For this analysis, we use the penalty $\frac{N+T}{N T} \log (\min (N, T))$ which is shown by Bai and $\mathrm{Ng}(2002)$ to have good finite sample properties. This criterion is referred to as $I C_{p 2}$. For both the original dataset and the subset of FRED-QD used for this comparison, $I C_{p 2}$ selects $r=4$ factors. 
McCracken and $\mathbf{N g}$
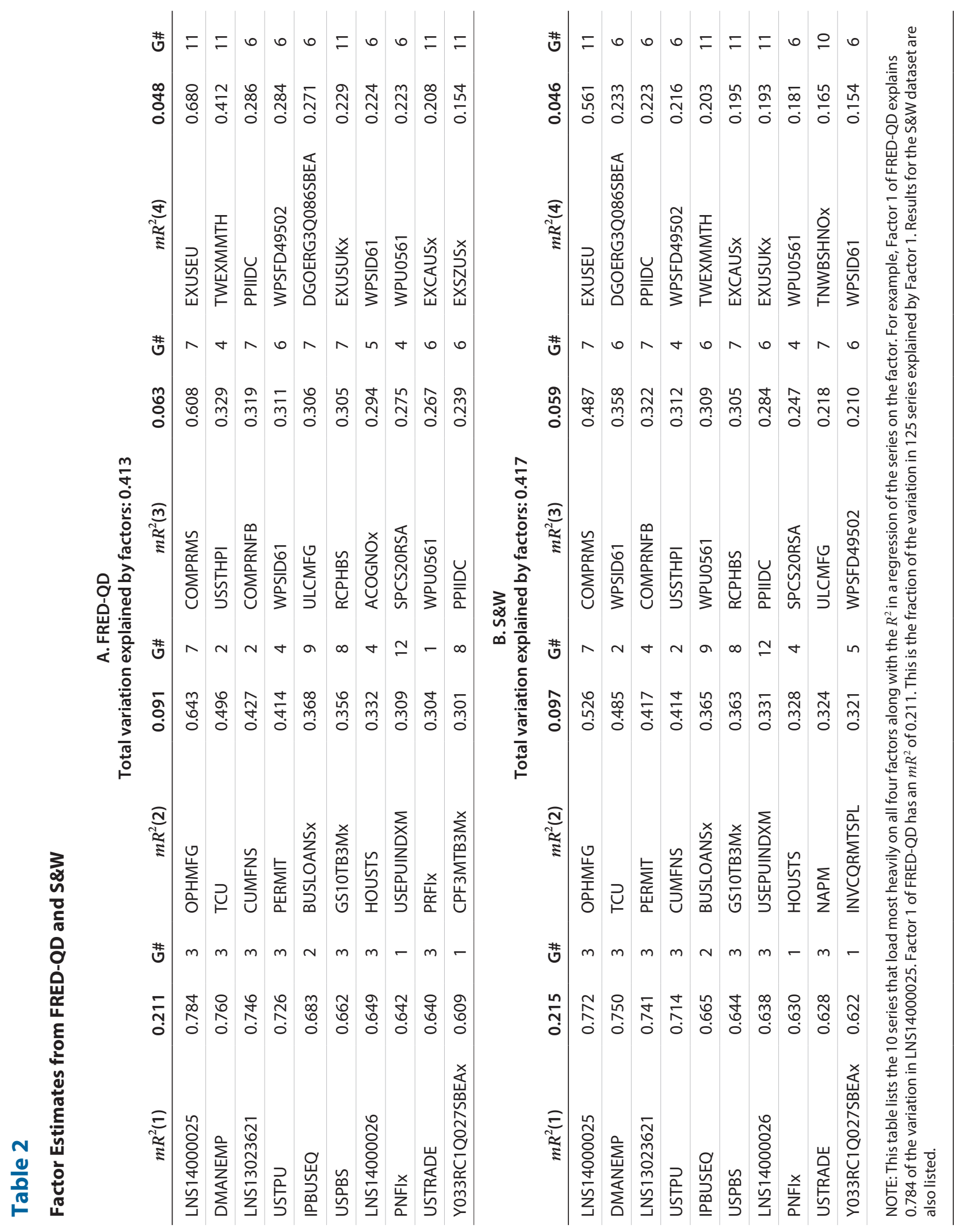


\section{McCracken and $\mathbf{N g}$}

In Figure 1 we plot the four factors based on each dataset. The National Bureau of Economic Research (NBER) recession dates are shown by the gray bars. Visually, each of the four factors is very similar across the entire sample. $\underline{T}$ This is particularly true for Factor 1 for which the two estimates are nearly identical and have a correlation exceeding 0.99 . The remaining three correlations are only marginally lower, with values of $0.988,0.968$, and 0.980 for Factors 2 through 4 , respectively.

While the figure gives a visual characterization of the similarities of the factors, it is instructive to provide a more quantitative comparison. We do this by identifying which series are best explained by the factors. To do so, we regress the $i$ th series in the dataset on a set of the $r$ factors. For $k=1, \ldots, r$, this yields coefficients of determination $R_{i}(k)^{2}$ for each series $i$. Because the factors are orthogonal and organized in decreasing order of their respective eigenvalues, the incremental explanatory power of factor $k$ for series $i$ is $m R_{i}^{2}(k)=R_{i}^{2}(k)-R_{i}^{2}(k-1)$, $k=2, \ldots, r$ with $m R_{i}^{2}(1)=R_{i}^{2}(1)$. The average importance of factor $k$ is $m R^{2}(k)=\frac{1}{N} \sum_{i=1}^{N} m R_{i}^{2}(k)$. Table 2 lists $m R^{2}(k)$ and the 10 series with the highest $m R_{i}^{2}(k)$ for factor $k$. Panel A does so for the factors estimated using FRED-QD, while Panel B does the same but with the original S\&W dataset. To simplify interpretation of the factors, we also include the group numbers for each of the 10 series.

A quick look at Table 2 immediately reinforces the visual similarity from Figure 1. Regardless of which dataset is used to estimate the factors, the total variation explained by all four factors is nearly the same (i.e., 0.41 ), and the $m R^{2}(k)$ values are nearly the same as well (i.e., $0.21,0.09,0.06$, and 0.05 for factors $k=1, \ldots, 4)$. The similarity also carries over to the top 10 series with the highest $m R_{i}^{2}(k)$ values. While the rank ordering of the series varies a bit, 10, 8 , 9 , and 9 of the top 10 series coincide across the four factors, respectively. This is convenient because it implies that the interpretation of the factors remains unchanged when using FRED-QD rather than the original S\&W dataset. Factor 1 is a real activity indicator that weighs heavily on series from the Employment, Industrial Production, and NIPA groups. Factor 2 is dominated by forward-looking series such as term interest rate spreads and inventories. Factor 3 has explanatory power concentrated in the Prices group as well as housing sector prices. Finally, Factor 4 is extensively weighted on both the Prices and Exchange Rates groups.

Figure 1 and Table 2 suggest that FRED-QD provides a reasonable replication of the original dataset - at least through the lens of PCA-based factor analysis. Even so, it also contains additional series not in the original S\&W dataset, and thus it is reasonable to wonder if those series provide additional information. Using all of the series and observations in FRED-QD, $I C_{p 2}$ selects three additional factors, bringing the total up to $r=7$. These are plotted in Figure 2. Factors 1 and 2 remain closely related to those constructed using the S\&W dataset, with correlations of 0.99 and 0.96 , respectively. Beyond that, the correlations drop off dramatically, with Factors 3 and 4 only exhibiting correlations of roughly 0.70 .

The similarities and differences are more readily seen in Table 3 . There we report the marginal $R^{2}$ values associated with the seven factors identified using the entirety of FRED-QD. As expected, Factors 1 and 2 retain the same interpretation as those reported in Figure 1 and Table 2. Factor 1 is a real activity factor that correlates strongly with series in the Employment 
Figure 2

\section{FRED-QD Factor Estimates}

A. Factor 1 Estimate

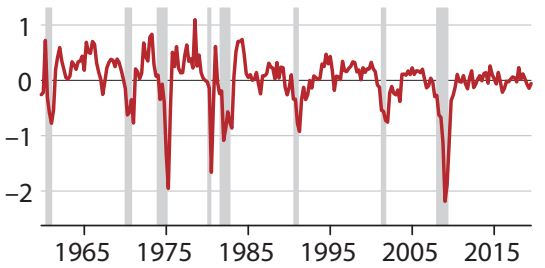

C. Factor 3 Estimate

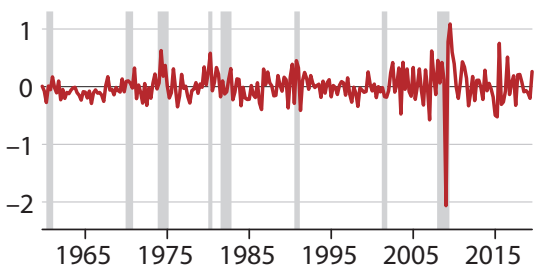

E. Factor 5 Estimate

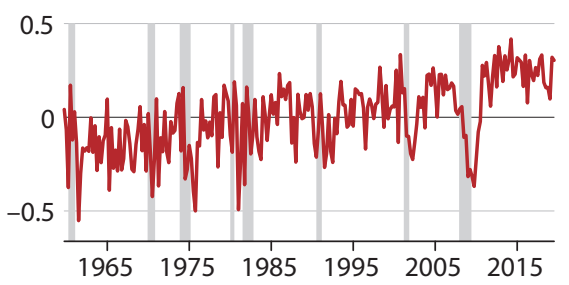

G. Factor 7 Estimate

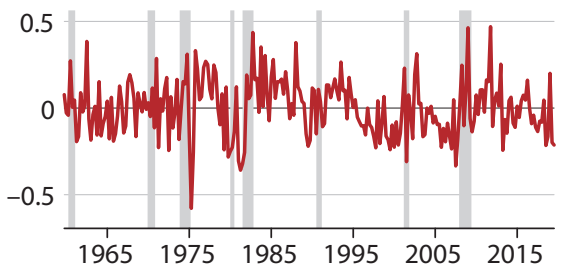

B. Factor 2 Estimate

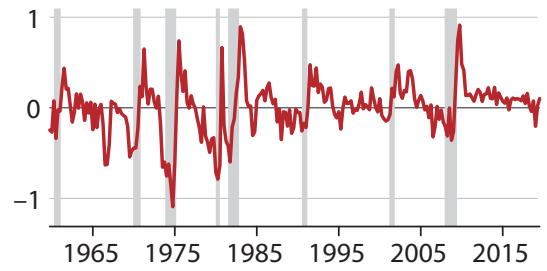

D. Factor 4 Estimate

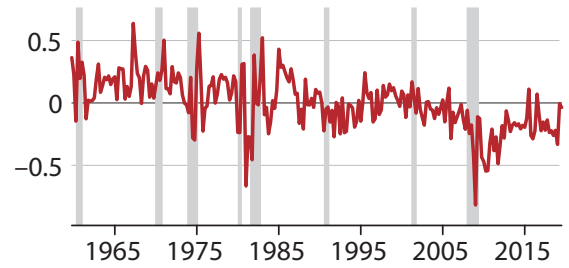

F. Factor 6 Estimate

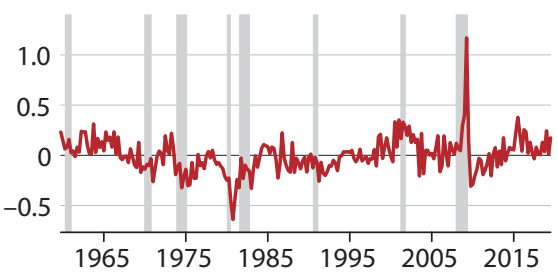

NOTE: This figure plots the PCA-based factors estimated using the full FRED-QD data set based on the benchmark transformation codes. Gray bars indicate recessions as determined by the NBER.

and Industrial Production groups, while Factor 2 remains a forward-looking factor that correlates heavily on interest rate term spreads as well as housing permits and starts. In contrast, while Factor 3 from the S\&W dataset was a mixture of consumer prices and housing prices, when estimated using FRED-QD, Factor 3 is a pure consumer price index (CPI) with all of the top $10 m R_{i}^{2}(3)$ values associated with the Prices group. In contrast, when using the full FRED-QD dataset, Factor 4 appears to be a second employment-oriented factor rather than a second prices-oriented factor, as we observed using the S\&W dataset. 


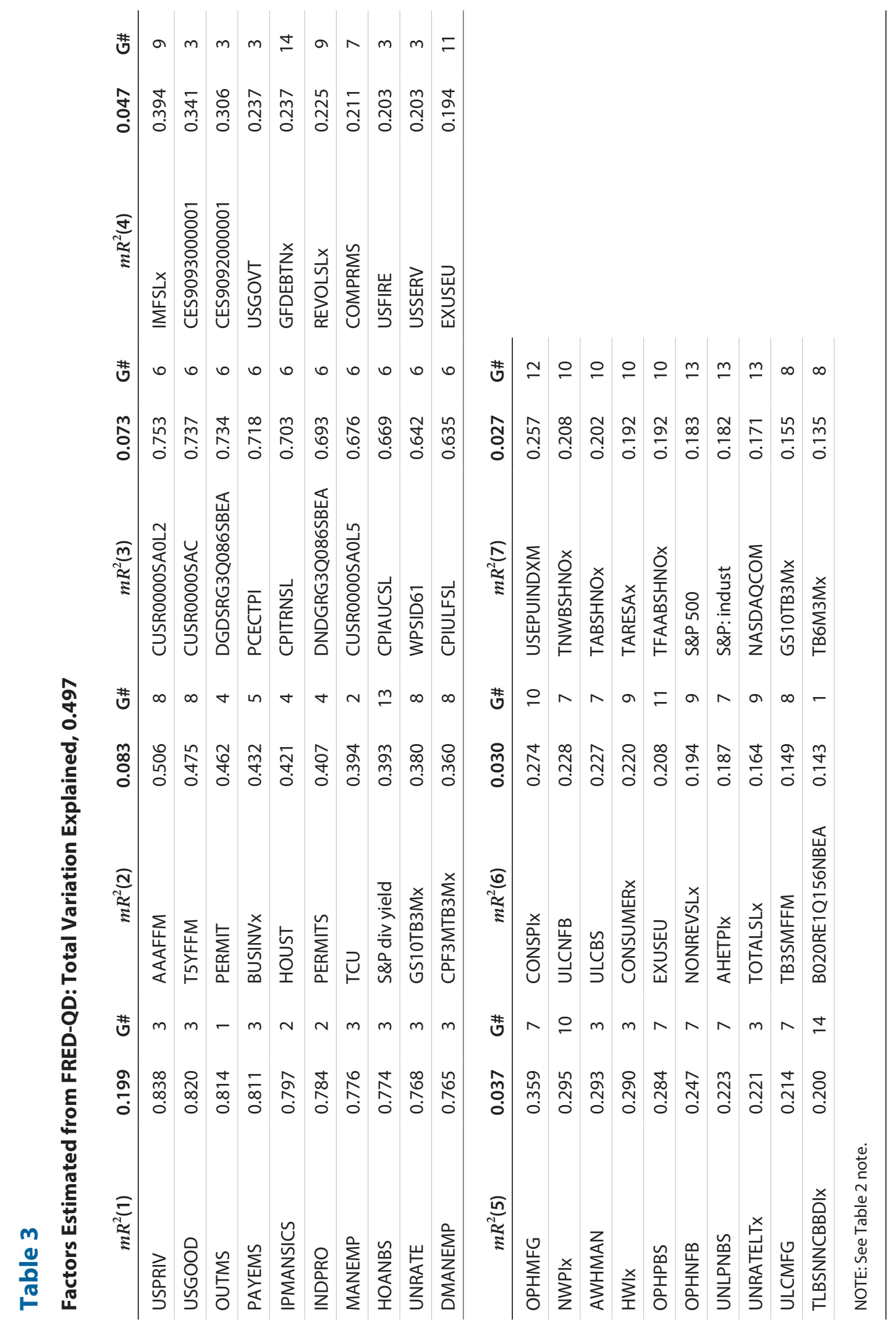


The interpretation of Factors 4 to 7 are less clear. While most of these factors exhibit considerable correlation with series in the Earnings and Productivity group (i.e., Group 7), a variety of other groups are represented. Factor 5 also correlates with Employment and both the Household and Non-Household Balance Sheet groups, while Factor 6 correlates with several series in the Money and Credit group. Finally, Factor 7 appears to be a weaker version of Factor 5 insofar as it too correlates heavily with several series in the Household Balance Sheet group. It is useful to note that these smaller factors are discarded using the criterion in Bai and $\mathrm{Ng}$ (2019b) that guards against outliers, an issue to which we now turn.

\section{OUTLIERS AND HIGH LEVERAGE OBSERVATIONS}

In this section, we provide a brief investigation into the importance of outliers and high leverage observations on the estimated factors. The statistics literature makes a distinction between these two concepts. - In a regression setting with predictors $x$ and predictand $y$, an observation is an outlier if the residual is far from its mean. In contrast, the observation is said to have high leverage if $x$ is far from the mean of its $x_{i}$ values and yet the corresponding residual is not large. In the context of factor analysis, analogous definitions exist and we consider them below. Loosely speaking, the $y$ variable is the factor and the $x$ variable is the underlying data used to estimate the factor.

Following S\&W, we define an outlier as an observation that deviates from the sample median by more than 10 interquartile ranges. By this definition, the S\&W dataset and the corresponding subset of FRED-QD each have seven outliers. These are identified in 1971:Q1 and 1997:Q1 for a consumer credit series, in 2008:Q4 for three producer price series, and in 2010:Q2 for federal employment and consumer loans. ${ }^{9}$ The full FRED-QD data has 30 outliers, 17 of which are found between 2008:Q1 and 2010:Q4 and are predominantly bank reserves variables. Two interest rate variables and a prices variable are also identified to be outliers in 1980:Q3 and Q4, as well as oil price in 1974:Q1 and six non-household balance sheet variables between 2017:Q4 and 2018:Q1.

Note, however, that this definition of an outlier does not depend on the value of the estimated factors. As such, it is not obvious that they should be removed prior to estimating the factors. $\frac{10}{}$ Without the outlier adjustment, the $I C_{p 2}$ criterion identifies eight factors in the data instead of seven. Nonetheless, the first six factors estimated with and without outlier adjustments are almost perfectly correlated, suggesting that the effect of these outliers on the largest factors is quite minimal.

In terms of high leverage observations, it seems likely that some of the 248 series, and (up to) 242 quarterly observations per series, are more important than others for estimating the factors. Using methods described in Mahoney (2011), we construct statistical leverage scores that inform us about the non-uniform structure of importance in the data. Consider a $T \times N$ data matrix $X$ with singular value decomposition $X=U \Sigma V^{\prime}$ and assumed to have a lowrank component of rank $r$. The factor estimates reported above can be expressed as $\left(\tilde{F}, \tilde{\Lambda}^{\prime}\right)=\left(\sqrt{T} U_{r}, \sqrt{N} V_{r} D_{r}\right)$. 
Figure 3

\section{FRED-QD Leverage Scores}

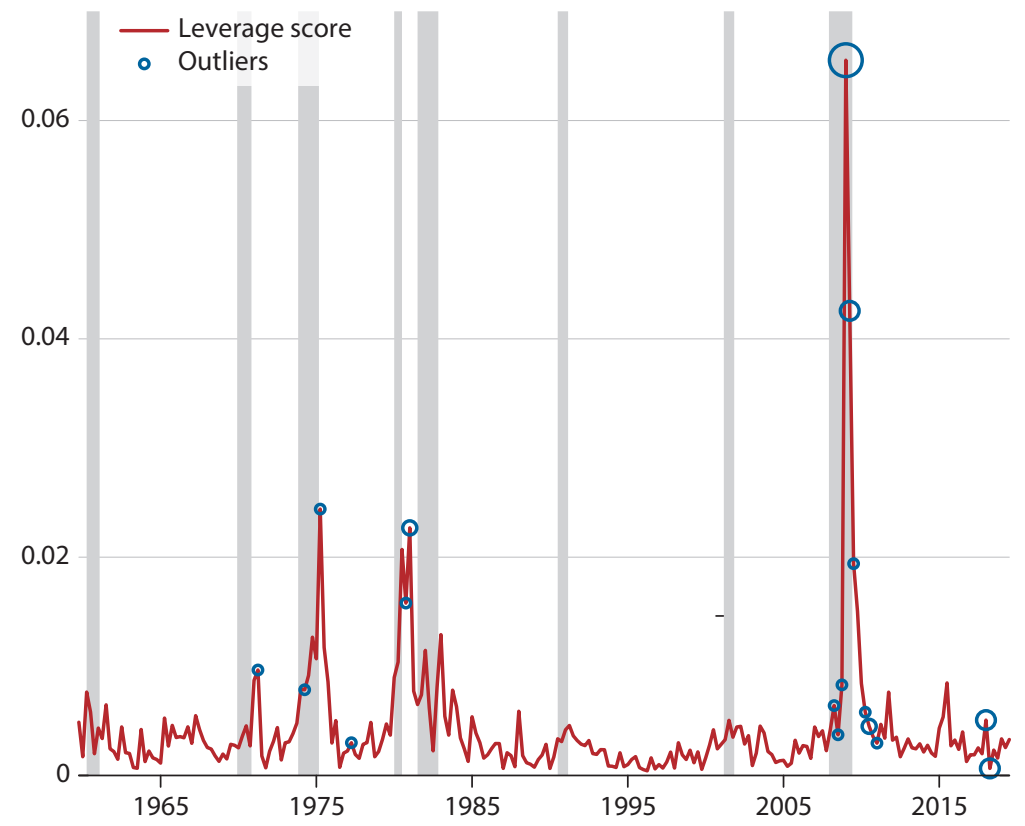

NOTE: This figure plots the statistical leverage score, $p_{t}$, of each quarter. Blue circles represent quarters where at least one value in a series is an outlier; circle size is relative to the number of outliers detected. Gray bars indicate recessions as determined by the NBER.

A different aspect of the eigenvectors will now be explored. Let $u_{(t)}$ be the $t$ th row of the $T \times r$ matrix of left singular vectors $U_{r}$, and $v^{(i)}$ be the ith column of the $r \times N$ matrix of right singular vectors $V_{r}^{\prime}$. Define the normalized row and column leverage scores as

$$
p_{t}=\frac{\left\|u_{(t)}\right\|_{2}^{2}}{\sum_{t=1}^{T}\left\|u_{(t)}\right\|_{2}^{2}}, \quad p^{i}=\frac{\left\|v^{(i)}\right\|_{2}^{2}}{\sum_{i=1}^{n}\left\|v^{(i)}\right\|_{2}^{2}} .
$$

As $\sum_{t=1}^{T} p_{t}=\sum_{i=1}^{N} p^{i}=1$, these probabilities also define an "importance sampling distribution" for the rows and the columns of $X$, respectively. The row scores are simply the diagonal entries of the "hat" matrix sometimes used to detect influential observations in regression settings. Here, it is used to evaluate the strength of each row of the top-r-left singular vectors, giving information about the relative importance of the time series data points. The column score evaluates the strength of each column of the top-r-right singular vectors and hence is informative about the relative importance of the data in the cross section.

We compute the row leverage scores for the full and balanced FRED-QD data with and without outlier adjustment. The results are similar, and hence to conserve space, in Figure 3 we plot the leverage scores for the full-sample of FRED-QD without outlier adjustment. If the information is uniformly dispersed over time, each of the $T$ observations should have a score 
of $\frac{1}{T}$. In the FRED-QD data, six data points account for 20 percent of the mass in $p_{t}: 2008: Q 4$, 2009:Q1, 1975:Q1, 1980:Q4, 1980:Q2, and 2009:Q2. These roughly coincide with the outliers detected by the interquartile-range method.

Turning to the column leverage scores, each $p^{i}$ should be $\frac{1}{N}$ if information in the series is evenly dispersed. This is apparently not the case, as the (unreported) histogram of $p^{i}$ is quite skewed. For the subpanel of FRED-QD data corresponding to the S\&W dataset, the series with the top three scores are the U.S./euro exchange rate (EXUSEU), WPSID61, and PPIDC, regardless of whether an outlier adjustment is made. For the full FRED-QD panel, the series with the top scores are COMPRMS, EXUSEU, and GS5 without outlier adjustment, and NWPIx, S\&P 500, and real household networth (TNWBSHNOx) with outlier adjustment. Apparently, the variables added to the full panel do change the information content of the panel. Nonetheless, these variables are already known to play an important role in business cycle modeling. This analysis simply reinforces their importance.

\section{TRANSFORMATION CODES}

As we noted earlier, the dataset provides benchmark transformation codes that are designed to make each series stationary. After having made the decision that the series should be managed in levels or log levels, the transformation codes are first and second differences based on whether the series is believed to be $I(0), I(1)$, or $I(2)$. In this section, we revisit the benchmark transformation codes and do so through the lens of unit root tests. In particular, we apply unit root tests to each series in FRED-QD to see whether or not the unit root tests imply the benchmark transformation codes.

For each series, we apply two variants of the Dickey-Fuller generalized least-squares (DFGLS) tests as delineated in Elliott, Rothenberg, and Stock (1996). These two tests differ only in how the number of autoregressive lags are chosen. One uses the Schwarz's Information Criterion (SIC) to choose the appropriate number of lags, and the other uses a Modified Akaike Information Criteron (MAIC), developed in $\mathrm{Ng}$ and Perron (2001). $\underline{11}$ In each case the maximum number of lags is based on the recommendation in Schwert (1989), and hence for a given sample size $T, k_{\max }=\left\lfloor 12(T / 100)^{1 / 4}\right\rfloor$.

We use the results of these tests to identify the appropriate transformation codes. For example, recall that for the DFGLS tests, the null hypothesis is that the series is $I(1)$. Hence, if we fail to reject, the series is differenced and the test is repeated until we reject the null. Depending on when this algorithm rejects the null determines the transformation code. For each test, and at each stage of the algorithm, we consider nominally 5 percent tests of the respective null.

For brevity we do not report the results of all the unit root tests. Instead, in Figure 4 we provide histograms of the implied transformation codes for all the series. 12 The first panel is the histogram of the codes reported in FRED-QD. All series have transformation codes of either 1, 2, 5, or 6, and hence no series are considered stationary in log levels (4) or second differences of levels (3). By far the bulk of the codes are $5 \mathrm{~s}$, and hence the series are considered 


\section{Figure 4}

Factors Estimated from FRED-QD: Total Variation Explained, 0.497

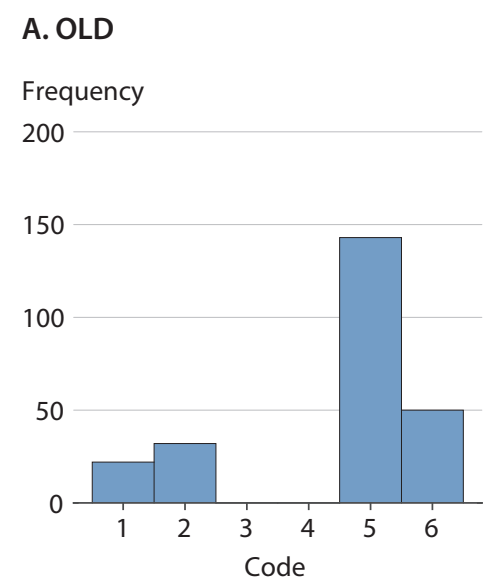

B. SIC

Frequency

200

C. MAIC

Frequency

200
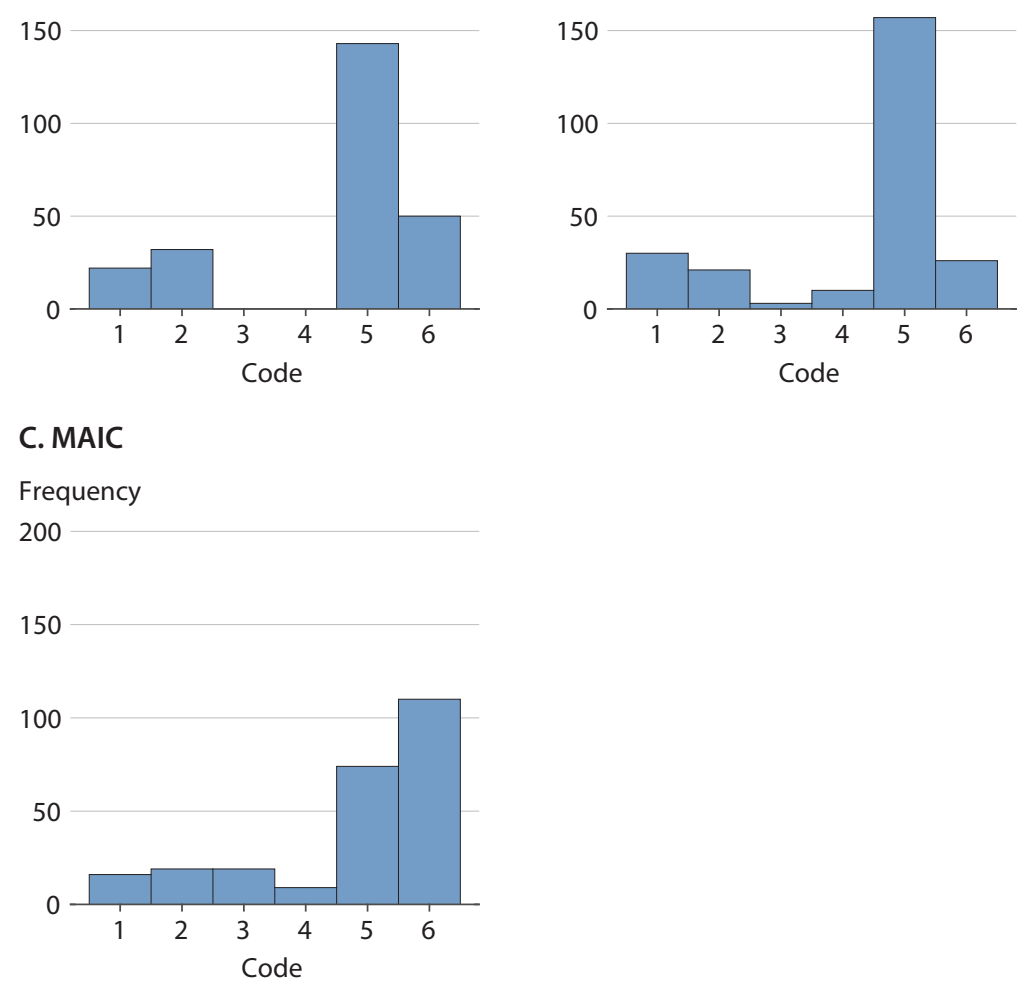

NOTE: Each panel provides a histogram of frequencies of transformation codes. "OLD" refers to the benchmark codes provided in FRED-QD. "SIC" and "MAIC" refer to codes implied by the associated DFGLS unit root test.

stationary in log-first differences. These patterns change when we consider the unit root-based transformation codes. The largest changes occur when using the MAIC variant of the DFGLS test. Here we find that much of the mass associated with a code of 5 has shifted into a code of 6 , leading to more than a doubling of the number of series that require double differencing in $\log$ levels. That said, some mass from the $5 \mathrm{~s}$ has settled into the $4 \mathrm{~s}$, suggesting that some of the series may be $I(0)$ in log levels rather than log-first differences. There is also a modest shift in mass from the $1 \mathrm{~s}$ and $2 \mathrm{~s}$ into $3 \mathrm{~s}$, and hence the tests indicate some of the series are stationary in the second difference of the levels. In contrast, the SIC-based DFGLS test implies more modest deviations from the original transformation codes. There remains almost no mass on the $3 \mathrm{~s}$ and $4 \mathrm{~s}$. The largest deviation from the benchmark codes comes from a shift of mass from the $6 \mathrm{~s}$ into the $5 \mathrm{~s}$, and hence the SIC-based test indicates that some of the series have been overdifferenced. 


\section{Table 4}

\section{FRED-QD Median Transformation Codes by Group}

\begin{tabular}{clccc} 
Group & \multicolumn{1}{c}{ Group name } & OLD & SIC & MAIC \\
\hline 1 & NIPA & 5 & 5 & 6 \\
\hline 2 & Industrial Production & 5 & 5 & 6 \\
\hline 3 & Employment and Unemployment & 5 & 5 & 5 \\
\hline 4 & Housing & 5 & 4.5 & 4.5 \\
\hline 5 & Inventories, Orders, and Sales & 5 & 5 & 6 \\
\hline 6 & Prices & 6 & 5 & 6 \\
\hline 7 & Earnings and Productivity & 5 & 5 & 6 \\
\hline 8 & Interest Rates & 1.5 & 1 & 2 \\
\hline 9 & Money and Credit & 5 & 5 & 5 \\
\hline 10 & Household Balance Sheets & 5 & 5 & 5 \\
\hline 11 & Exchange Rates & 5 & 5 & 1 \\
\hline 12 & Other & 1.5 & 1 & 5 \\
\hline 13 & Stock Markets & 5 & 5 & 5 \\
\hline 14 & Non-Household Balance Sheets & 5 & 5 & 5 \\
\hline
\end{tabular}

The histograms convey the fact that the unit root tests can imply transformation codes that don't align with the benchmark codes. Nevertheless, they do not convey where the changes are coming from. To address this issue, in Table 4 we report the median transformation codes by group. For the MAIC-based tests, much of the shift toward log second differences occurs in the NIPA, Industrial Production, and Earnings and Productivity groups. In contrast, for the SIC-based tests, the biggest change occurs for Prices, in which case the test recommends treating Prices as log first differences instead of log second differences. Both versions of the DFGLS tests disagree with the benchmark codes for Housing, of which several of the series are considered stationary in log levels and hence do not need to be differenced.

It's clear that the unit root tests recommend changes in some of the transformations. Even so, it's worth keeping in mind that many of the unit root-implied codes continue to coincide with the benchmark codes. It therefore need not be the case that factors based on the benchmark codes deviate significantly from factors based on the unit root codes. In Figure 5 we plot the first four factors based on the benchmark codes along with the corresponding factors constructed after using the unit root test determined codes. For the first factor, the SIC- and benchmark-implied factors largely coincide and exhibit a correlation of 0.95 . In contrast, the MAIC-based variant deviates substantially from that constructed using the benchmark codes, with which they have a modest correlation of 0.56 . For the remaining factors, substantial differences exist among the unit root-implied factors and those based on the benchmark codes. 


\section{McCracken and $\mathbf{N g}$}

Figure 5

\section{FRED-QD Factor Estimates by Method of Series Transformation}

\section{A. Factor 1 Estimates}

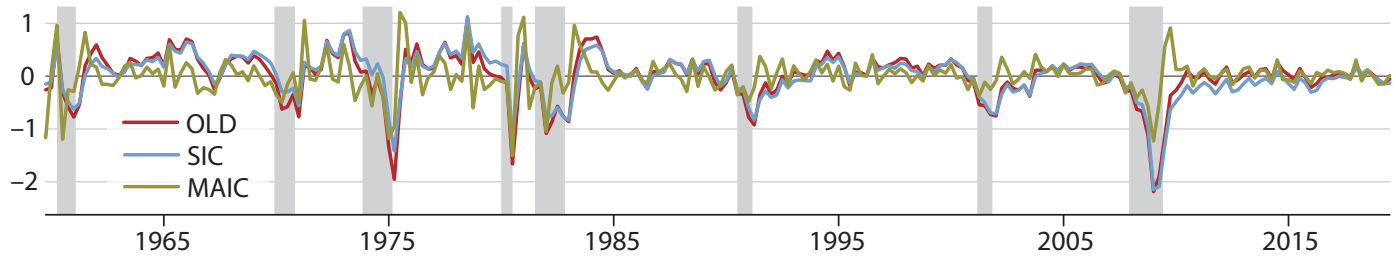

\section{B. Factor 2 Estimates}

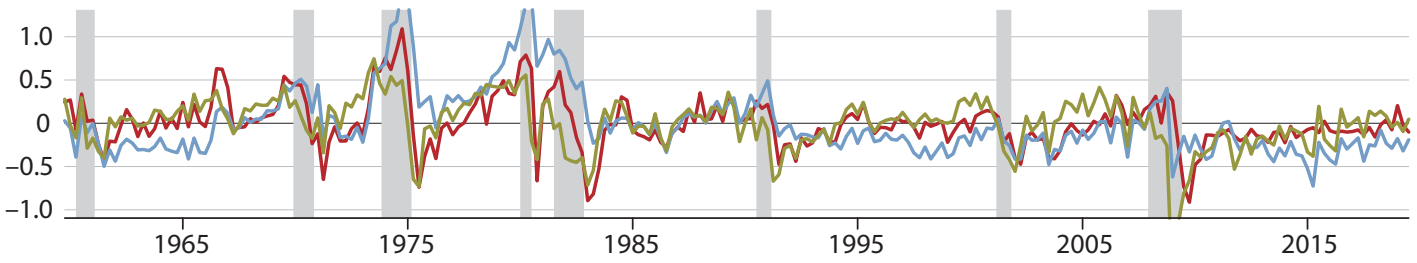

\section{Factor 3 Estimates}

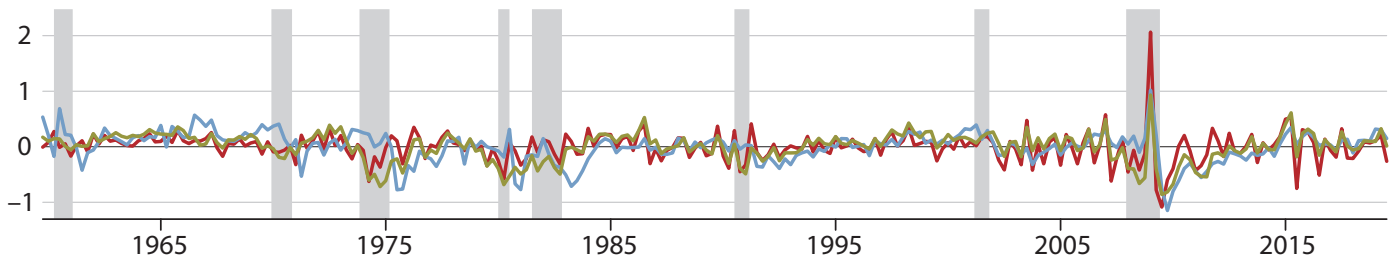

D. Factor 4 Estimates

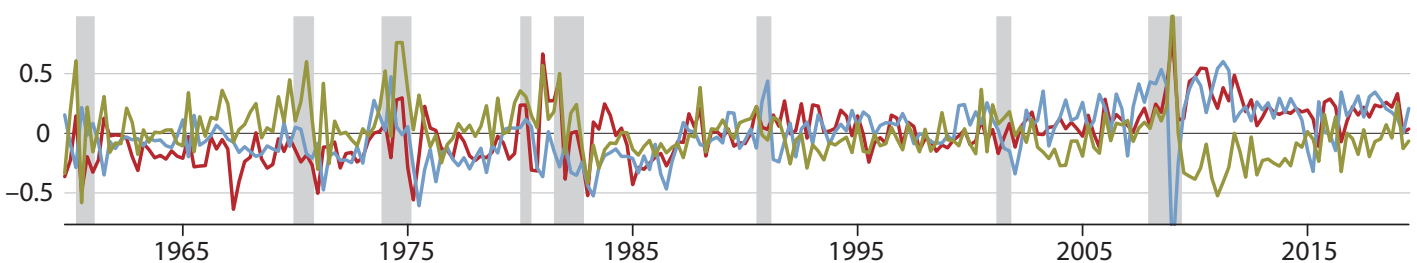

NOTE: This figures plots the first four PCA-based factors corresponding to the benchmark (OLD) codes and those implied by the unit root tests (SIC and MAIC). Gray bars indicate recessions as determined by the NBER.

In Table 5, more detailed evidence on the differences in the factors can be gleaned from the marginal $R^{2}$ values for the factors plotted in Figure 5. Rather than go through these in detail we make only a few notable observations. One noticeable distinction among the factors is that while the MAIC-based factors remain heavily concentrated in the Employment and Industrial Production groups, the $m R^{2}(1)$ values are substantially lower than those associated with the benchmark and SIC-based codes. This likely follows from the propensity of the MAIC-based unit root tests to treat many NIPA and employment series as $I(2)$ rather than $I(1)$, which 
McCracken and Ng
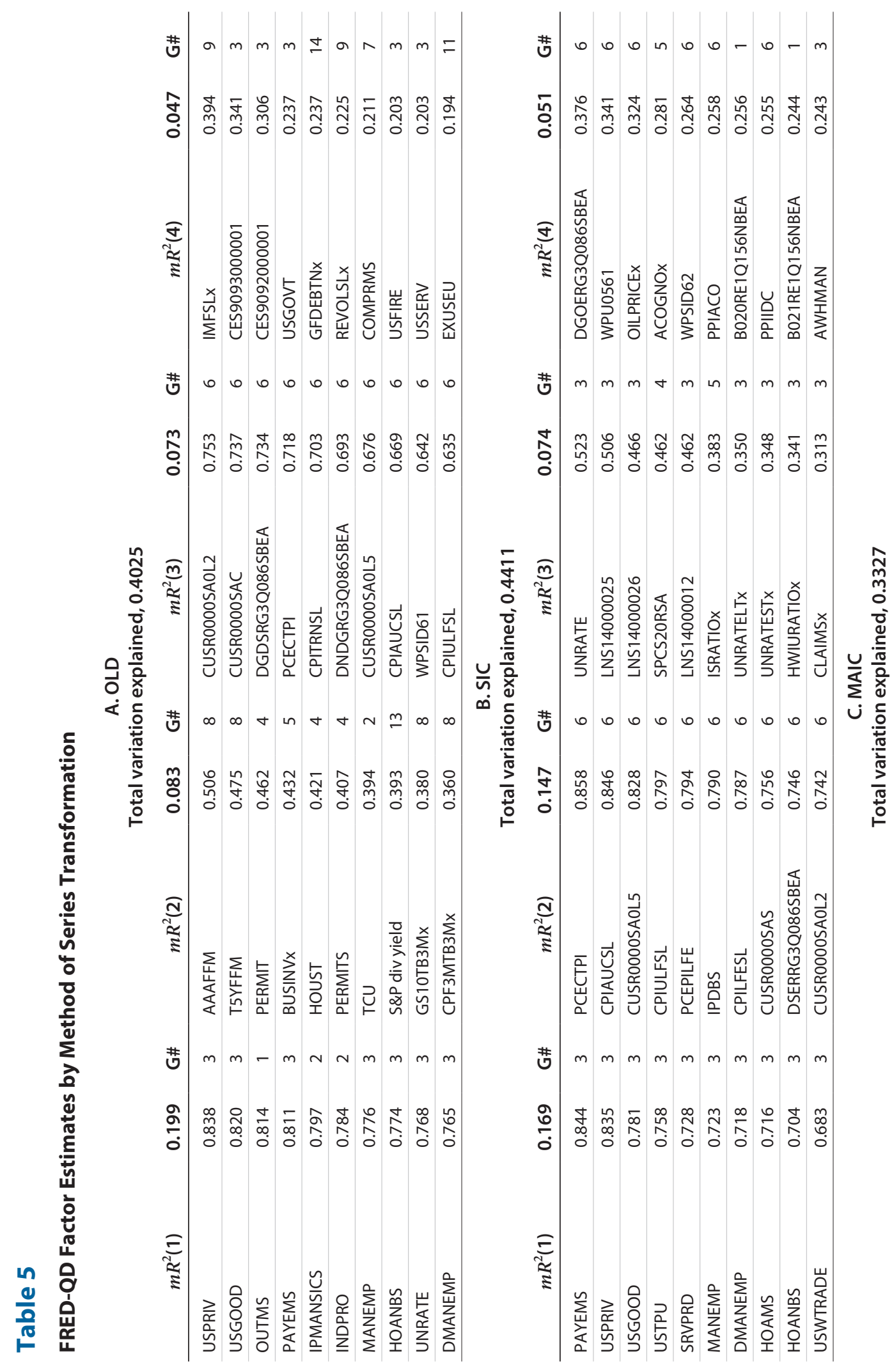

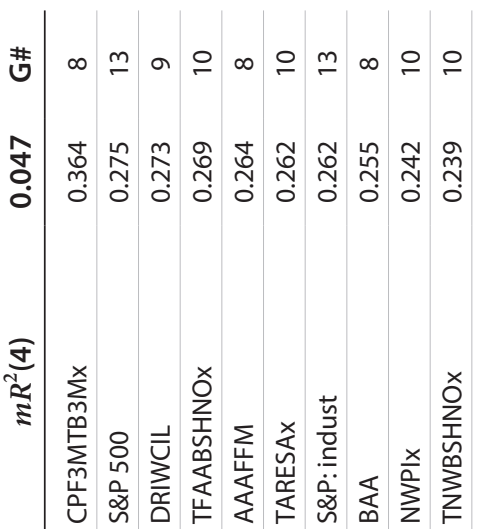

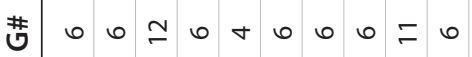

:。ำ

-

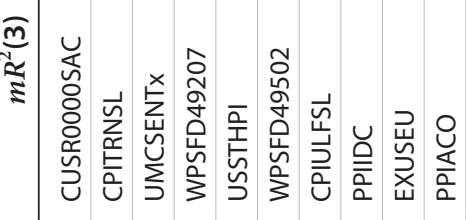

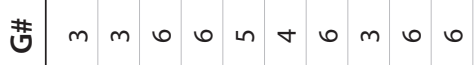

可

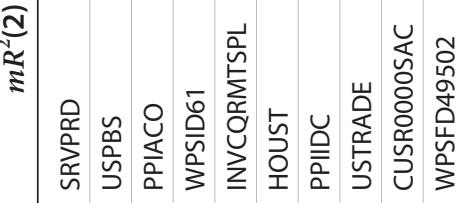

\#-

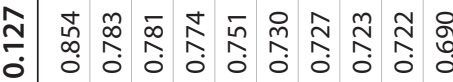

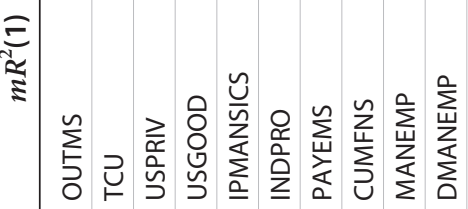




\section{McCracken and $\mathbf{~ g g}$}

apparently leads to a loss of information due to overdifferencing. Another is the relatively clear interpretability of the SIC-based factors. Factor 1 is a clear employment factor, while Factor 2 is a pure consumer prices factor. Factor 3 is arguably an unemployment factor, and Factor 4 is heavily correlated with producer prices with an emphasis on energy and, specifically, oil prices.

\section{PREDICTABILITY OF FACTOR-BASED MODELS}

In this section, we investigate the usefulness of factors for predicting macroeconomic aggregates. The structure of the forecasting exercise is motivated by a similar forecasting exercise conducted by Stock and Watson (2012b). Specifically, we construct one- and four-quarterahead forecasts of real GDP (log level), industrial production (log level), the unemployment rate (level), and the federal funds rate (level), as well as the CPI, personal consumption expenditures (PCE), GDP deflator, and PPI price indices (each in log level). These variables were chosen based on the results of the unit root tests in the previous section, with an eye toward emphasizing the role that transformation codes have on the predictive content of factors. For each permutation of the eight dependent variables $Y$ and two horizons $h$, we have three goals: (i) document that the FRED-QD factors have predictive content above and beyond that contained in a baseline autoregressive model, (ii) document whether the choice of transformation codes can have a material effect on the predictive content of factors extracted from FRED-QD, and (iii) document those factors that exhibit the most predictive content for the target variables.

In each case, the models used for forecasting take the direct multistep form

$$
y_{t}^{(h)}=\alpha_{h}+\sum_{j=0}^{p-1} \beta_{j}^{(h)} y_{t-h-j}+\delta^{(h)^{\prime}} f_{t-h}+\varepsilon_{t}^{(h)},
$$

where

$$
y_{t}^{(h)}=\left\{\begin{array}{cc}
Y_{t} & \text { if } Y_{t} \text { is } I(0) \\
Y_{t}-Y_{t-h} & \text { if } Y_{t} \text { is } I(1) \\
Y_{t}-Y_{t-h}-h \Delta Y_{t-h} & \text { if } Y_{t} \text { is } I(2)
\end{array}\right\} \text {. }
$$

For brevity, when $h=1$ we drop the superscript and define $y_{t}^{(1)}$ as $y_{t}$. At each forecast origin, the model is estimated by ordinary least squares and the $h$-step-ahead forecast of $y_{t+h}^{(h)}$ is then constructed as

$$
\hat{y}_{t, h}^{(h)}=\hat{\alpha}_{h, t}+\sum_{j=0}^{p-1} \hat{\beta}_{j, t}^{(h)} y_{t-j}+\hat{\delta}_{t}^{(h)^{\prime}} f_{t}
$$

Forecasts of $Y_{t+h}$ are then computed in accordance with the order of integration of $Y$ :

$$
\hat{Y}_{t, h}=\left\{\begin{array}{cc}
\hat{y}_{t, h}^{(h)} & \text { if } Y_{t} \text { is } I(0) \\
Y_{t}+\hat{y}_{t, h}^{(h)} & \text { if } Y_{t} \text { is } I(1) \\
Y_{t}+h \Delta Y_{t}+\hat{y}_{t, h}^{(h)} & \text { if } Y_{t} \text { is } I(2)
\end{array}\right\} .
$$


Following Stock and Watson (2012b), we fix the number of autoregressive lags $p$ at four and only consider a single lag of the factor(s). Since it is not obvious which of the seven factors should be used to forecast any particular target variable, and since those factors could vary by horizon, we consider all $2^{7}-1=127$ possible choices of $f_{t}$ as a potential predictor. Hence, in some cases, $f$ is a scalar consisting of just one of the seven possible factors, while in other models $f$ is a vector consisting of up to all seven factors.

All models are estimated using a rolling window of 106 (109) observations when $h=1$ (4). The first forecast origin is $R=1985: \mathrm{Q} 1+h$, and the last forecast origin is $T=2018: \mathrm{Q} 4-h$, for a total of $P=134$ (128) forecasts. At each forecast origin, we estimate the factors two different ways. For the first, we use the benchmark transformation codes provided in FRED-QD. For the second, at each forecast origin, we perform unit root tests on all series in FRED-QD using the past 106 (109) observations when $h=1$ (4). Based on the outcome of these tests, we select transformation codes using the same algorithms described in the previous subsection. For brevity, we only consider the SIC-based DFGLS unit root test in this forecasting exercise. Using the MAIC-based unit root test leads to different results. Our goal is not to provide the "correct" set of results, but rather to demonstrate that sticking to previously established transformation codes may lead to inferior results. $\underline{13}$

It's important to keep in mind that by taking a rolling-window approach to forecasting, we have potentially time-varying transformation codes and this has multiple effects on our forecasting exercise. Obviously, different transformation codes lead to distinct estimated factors as shown in Figure 5. In addition, given our direct multistep forecasting environment, different transformation codes also lead to time-varying definitions of $y^{(h)}$. For this reason, we measure accuracy of the forecasts relative to $Y$ rather than $y^{(h)}$. In particular, we evaluate accuracy of the forecasts under quadratic loss using mean-squared errors $P^{-1} \sum_{t=R}^{T}\left(Y_{t+h}-\hat{Y}_{t, h}\right)^{2}$.

For each target variable $Y$ and horizon $h$, there is a benchmark $A R(4)$ model that is estimated using the original (OLD) transformation codes. In addition, there are 127 models that augment the benchmark $A R(4)$, with at least one factor formed using the OLD transformation codes. The same is done using transformation codes based on the unit-root-testing algorithm (NEW). This leads to 128 more models, including an $A R(4)$ based on the NEW codes and 127 models that augment this $A R(4)$ with at least one of the seven factors.

For each of the 254 models that include at least one factor, we conduct a one-sided test of the null that the factors do not contribute finite-sample predictive content relative to the benchmark $A R(4)$. The null is stated in the context of the test of unconditional finite-sample predictive ability advocated by Giacomini and White (2006). However, in contrast to their recommended testing procedure, we follow Coroneo and Fabrizio (2020) and apply a fixed-b asymptotic approximation to the test statistic. Specifically, for each model $j=1, \ldots, 254$ that includes at least one factor, the test statistic takes the form $P^{-1 / 2} \sum_{t=R}^{T}\left(\hat{u}_{t+h, A R}^{2}-\hat{\mathcal{u}}_{t+h, j}^{2}\right) / \hat{\omega}_{j}$, where $\hat{\omega}_{j}^{2}$ is an estimate of the long-run variance of $\hat{u}_{t+h, A R}^{2}-\hat{u}_{t+h, j}^{2}$. This is estimated using the Bartlett kernel and bandwidth $\lfloor 1.3 \sqrt{P}\rfloor+1$ as advocated in Lazarus et al. (2018). Critical values for the asymptotic distribution are approximated using the formula provided in Table 1 of Kiefer and Vogelsang (2005, p. 1146). 


\section{McCracken and $\mathbf{~ g g}$}

While this testing procedure allows us to ascertain whether the factors exhibit finitesample predictive content beyond that in the benchmark $A R(4)$, there is an obvious multipletesting problem. To mitigate the potential for multiple testing, we provide complementary evidence on accuracy using the model confidence set procedure advocated by Hansen, Lunde, and Nason (2011). This allows us to identify the subset of all 256 models that are statistically as accurate as the single most accurate model. Note that this information is related to, but not the same as, the previous test comparing each model to the benchmark. For example, it could be the case that the benchmark is the best model, and hence factors do not provide additional predictive content. Even so, many of the factor-based models may be contained in the model confidence set because they are approximately as accurate as the benchmark. With this difference of interpretation in mind, we use the $T_{R, \mathcal{M}} \equiv \max _{i, j \in \mathcal{M}}\left|t_{i, j}\right|$ statistic when implementing the model confidence set procedure. The distribution of this test statistic is approximated using a circular block bootstrap with block length $l=12$ using software distributed by Sheppard (2018). To help identify the most-accurate models, we use a restrictive significance level of 25 percent-that is, the level associated with the model confidence set $\mathcal{M}_{75} \cdot \frac{14}{}$

Rather than report all of the testing results, we focus on a concise subset that provides evidence on our three forecasting goals. For each permutation of target variable $Y$ and horizon $h$, we report the root-mean-squared error (RMSE) for the benchmark $A R(4)$, along with the relative RMSEs associated with the 10 most-accurate models. An asterisk denotes whether the models were more accurate than the $A R(4)$ at the 5 percent level using the fixed-b critical values. In addition, we report the number of OLD and NEW models that outperform the benchmark $A R(4)$. Finally, we report the number of models contained in the model confidence set. Since we want to identify the importance of the transformation codes, we also specify the number of models in the model confidence set that use the NEW factors based on the unitroot-driven transformation codes.

Tables 6 and 7 provide the results. In the first table we focus on the real and financial target variables, while in the second we focus on the price series. In Table 6 we find numerous evidence that the factors can provide additional predictive content beyond that of the benchmark $A R(4)$. For all four target variables and at both forecast horizons, the number of factor-based models that significantly outperform the benchmark range from a low of three models when forecasting the federal funds rate at the one-quarter horizon to a high of 142 models when forecasting the unemployment rate at the four-quarter horizon. To be fair, many of those that outperform the benchmark only do so to a modest degree. The largest gains occur for the unemployment rate at the four-quarter horizon, where accuracy is improved by a substantial 25 percent. For the other target variables and/or horizons, the largest gains range from 17 percent to as low as 3 percent.

One obvious feature of Table 6 is the dominance of the factors constructed using the OLD transformation codes. Across all target variables and horizons, exactly 16 out of a possible 80 top 10 most-accurate models are based on factors estimated using the NEW transformation codes. Seven of these instances occur when forecasting GDP growth, another seven occur when forecasting the federal funds rate, and the remaining two occur when forecasting the unemployment rate; in all cases these occur at the four-quarter horizon. In addition, for all 
McCracken and $\mathbf{~ g g}$
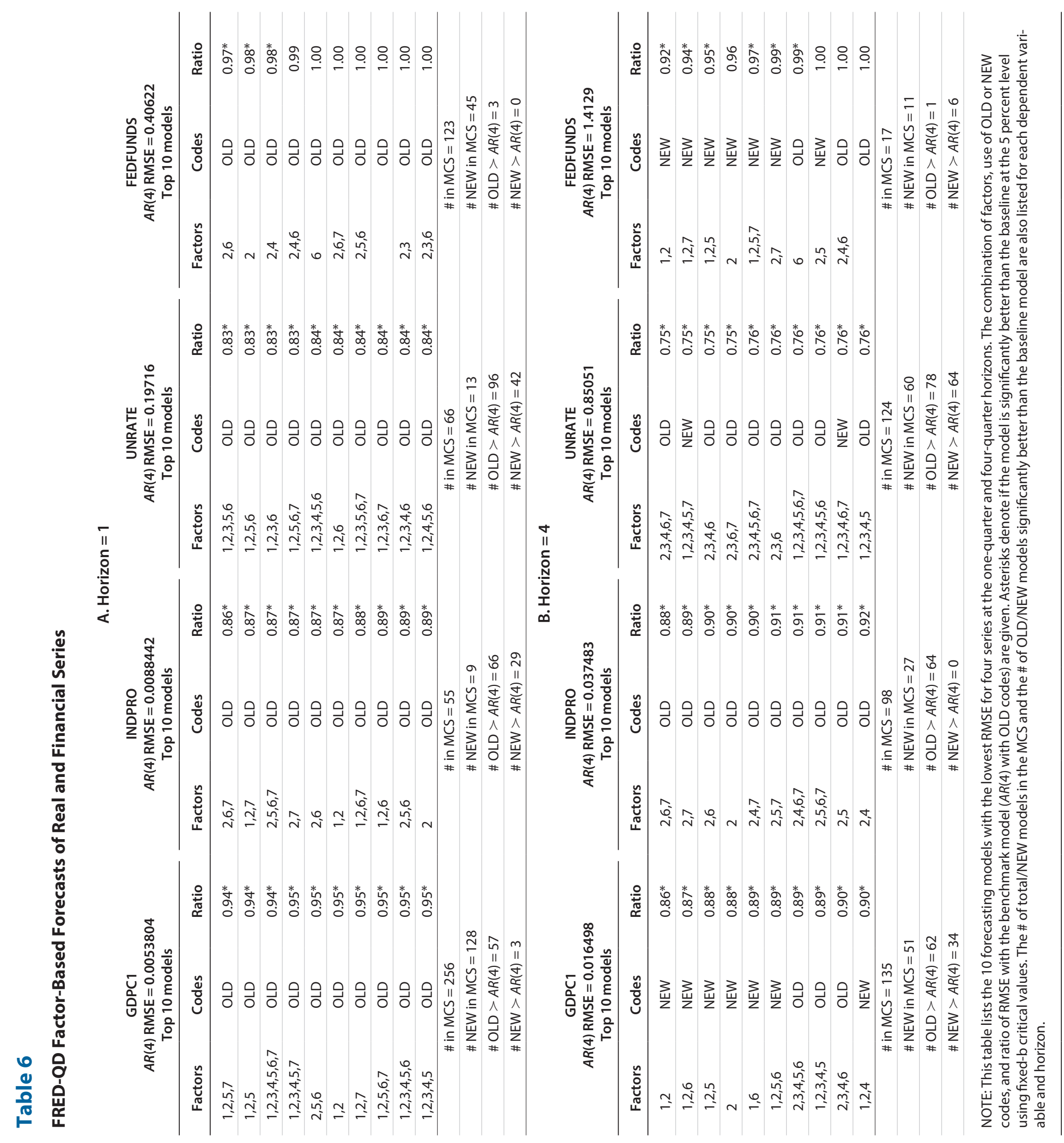


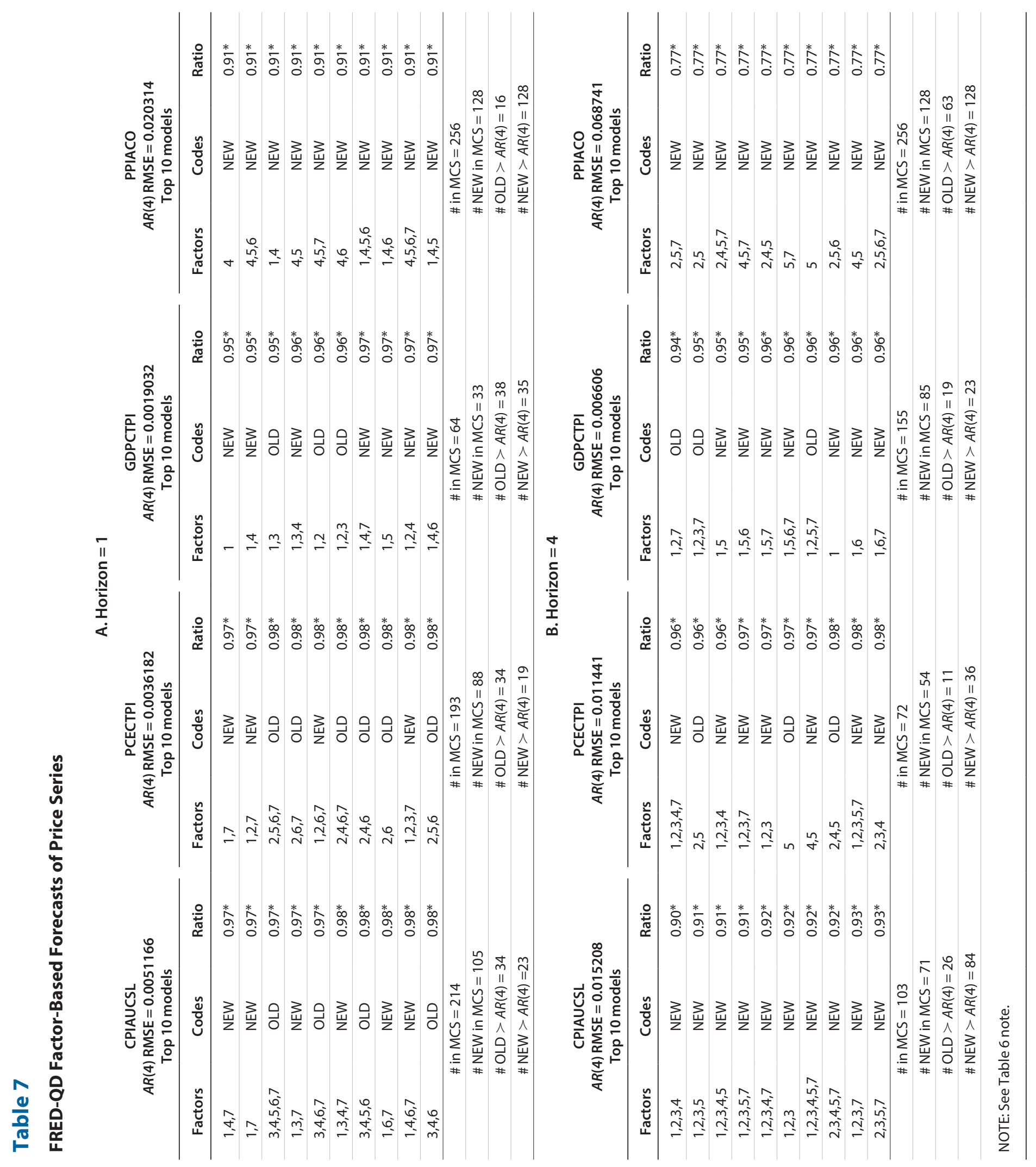


but one permutation of target variable and horizon, there are more models based on the OLD transformation codes that outperform the $A R(4)$ benchmark.

Among those factor-based models that perform in the top 10, it isn't obvious that one particular factor is dominant and should always be used when forecasting. Even so, it is true that Factors 1 or 2 occur in all but two of the top 10 factor-based models. While that might suggest that those factors associated with the largest eigenvalues provide the most predictive content, one should not conclude the contributions are monotone. There are many instances, like that when forecasting industrial production at either horizon, where Factors 2, 6, and 7 are included, but Factors 1, 3, 4, and 5 are not. It's also worth noting that the number of factors necessary to improve accuracy relative to the benchmark $A R(4)$ varies across series and, to a lesser extent, horizon. When forecasting the federal funds rate, maximal gains are achieved when including only two factors, but when forecasting the unemployment rate, the best models include five factors. In fact, there are instances in which including all seven factors in the model lead to forecasts of the unemployment rate and GDP growth that outperform those based on the benchmark $A R(4)$ model.

Moving to Table 7, that associated with predicting the four price series, we again find substantial evidence that the factors can provide marginal predictive content beyond the benchmark $A R(4)$. In some cases, such as when forecasting the GDP deflator at the four-quarter horizon, the number of factor-based models that have marginal predictive content is as low as 42 , but in other cases, such as when forecasting PPI at the same horizon, the number is as high as 191. Relative to the benefits of using factor-based models observed in Table 6, the top gains are typically smaller. When forecasting PPI at the four-quarter horizon, the gains are as large as 23 percent but are less than 10 percent for all other permutations of the target variable and horizon.

But in contrast to the results in Table 6, when forecasting prices, factor-based models using the NEW transformation codes generally dominate those that use the OLD codes. Among the 80 possible top 10 models, only 19 are based on models that use the OLD transformation codes. Interestingly, none of these instances occur when forecasting PPI, which is dominated by factors estimated using the NEW transformation codes. In addition, relative to Table 6, there tends to be more models in the confidence set that use the NEW transformation codes. Similarly, relative to Table 6, a larger number of factor models that use the NEW transformation codes outperform the benchmark $A R(4)$-and do so especially at the longer forecast horizon.

To understand why the NEW transformation codes work better for forecasting prices, recall that in Section 5 we found that the transformation codes implied by the SIC-based unit root tests treated many of the price series as $I(1)$ in logs, whereas the OLD codes treat them as $I(2)$ in logs. If the price series are $I(1)$, but are treated as $I(2)$, then they are being overdifferenced and information is lost. This has two effects: (i) It affects the information content in the factors, and (ii) it removes the predictable component of the price variable being forecasted. The former of these could, hypothetically, have affected forecasts of the real variables in Table 6 but was not sufficient to outperform factors constructed using the OLD transformation codes. In contrast, since prices are being forecasted in Table 7, the latter effect has a direct impact and thus seems likely to have played an important role. 


\section{McCracken and $\mathbf{~ g g}$}

In terms of which factors are most useful for forecasting, there is a bit more heterogeneity when forecasting prices. In Table 6, nearly every top 10 model had at least Factors 1 or 2 based on either the OLD or NEW transformation codes. While it is the case that a majority of the top 10 models in Table 7 contain Factors 1 or 2, some of the best models include neither Factors 1 or 2 and instead include Factors 4 or 5 -this is particularly true when forecasting PPI for either forecasting horizon. Nevertheless, it remains true that many of the top 10 models contain more than just one or two factors and, in fact, several include as many as five or six factors.

\section{CONCLUSION}

As was the case for FRED-MD, the purpose of introducing FRED-QD is to provide easy access to a large set of macroeconomic data that can be used to conduct research using "bigdata" methods. The primary difference between the two datasets is simply that FRED-QD provides quarterly frequency data and, as such, permits the inclusion of lower-frequency series such as those from the NIPA releases. Regardless of this difference, like FRED-MD, the dataset has been - and will continue to be-updated by the data specialists at FRED ${ }^{\circledast}$ on a regular basis to account for newly released data, data revisions, and other complicating issues that sporadically arise with data collection. We (again!) sincerely thank them for their support in this work.

\section{APPENDIX}

FRED-QD is a quarterly frequency companion to FRED-MD. It is designed to emulate the dataset used in Stock and Watson (2012a) but also contains several additional series. The columns in Table A1 denote the following: (i) "ID" denotes the series number; (ii) "S\&W ID" denotes the series number in Stock and Watson (2012a); (iii) TCODE denotes one of the following data transformations for a series $x$ : (1) no transformation, (2) $\Delta x_{t}$, (3) $\Delta^{2} x_{t}$, (4) $\log \left(x_{t}\right)$, (5) $\Delta \log \left(x_{t}\right),(6) \Delta^{2} \log \left(x_{t}\right)$, and (7) $\Delta\left(x_{t} / x_{t-1}-1.0\right)$; (iv) "S\&W factors" denotes whether a series was used in Stock and Watson (2012a) when constructing factors (i.e., 1 is yes and 0 is no); (v) "FRED ${ }^{\circledR}$ mnemonic" denotes the mnemonic we use for the dataset; (vi) "S\&W mnemonic" denotes the mnemonic used in Stock and Watson (2012a); and (vii) "Description" gives a brief definition of the series. The series are loosely grouped based on Stock and Watson (2012a).

Details on construction of the data will be forthcoming, but a few general comments are in order. First, if the FRED ${ }^{\infty}$ mnemonic does not end in "x," then the series comes directly from the FRED ${ }^{\circledR}$ data service (e.g., PCECC96 is real PCE). Otherwise, the series is a modified variant of a series from FRED ${ }^{\oplus}$ (e.g., PCDGx is nominal PCE durables, which is manually deflated using the PCE price index). The exception to this rule is the $\mathrm{S} \& \mathrm{P}$ data, which is taken from public sources. Lastly, monthly frequency series are aggregated to a quarterly frequency using averages. 


\section{Table A1A}

\section{Group 1: NIPA}

\begin{tabular}{|c|c|c|c|c|c|c|c|}
\hline Number & ID \# & $\begin{array}{l}\text { S\&W } \\
\text { ID \# }\end{array}$ & TCODE & $\begin{array}{c}\text { S\&W } \\
\text { factors }\end{array}$ & $\begin{array}{c}\text { FRED }^{\circledR} \\
\text { mnemonic }\end{array}$ & $\begin{array}{c}\text { S\&W } \\
\text { mnemonic }\end{array}$ & Description \\
\hline 1 & 1 & 1 & 5 & 0 & GDPC1 & GDP & $\begin{array}{l}\text { Real GDP, } 3 \text { decimal (billions of chained } 2012 \\
\text { dollars) }\end{array}$ \\
\hline 2 & 2 & 2 & 5 & 0 & PCECC96 & Consumption & Real PCE (billions of chained 2012 dollars) \\
\hline 3 & 3 & 3 & 5 & 1 & PCDGX & Cons:Dur & $\begin{array}{l}\text { Real PCE expenditures: durable goods (billions } \\
\text { of chained } 2012 \text { dollars), deflated using PCE }\end{array}$ \\
\hline 5 & 5 & 5 & 5 & 1 & PCNDx & Cons:NonDur & $\begin{array}{l}\text { Real PCE: nondurable goods (billions of } 2012 \\
\text { dollars), deflated using PCE }\end{array}$ \\
\hline 6 & 6 & 6 & 5 & 0 & GPDIC1 & Investment & $\begin{array}{l}\text { Real gross private domestic investment, } \\
3 \text { decimal (billions of chained } 2012 \text { dollars) }\end{array}$ \\
\hline 9 & 9 & 9 & 5 & 1 & PNFIx & Fixlnv:NonRes & $\begin{array}{l}\text { Real private fixed investment: nonresidential } \\
\text { (billions of chained } 2012 \text { dollars), deflated } \\
\text { using PCE }\end{array}$ \\
\hline 10 & 10 & 10 & 5 & 1 & PRFIx & Fixedlnv:Res & $\begin{array}{l}\text { Real private fixed investment: residential } \\
\text { (billions of chained } 2012 \text { dollars), deflated } \\
\text { using PCE }\end{array}$ \\
\hline 11 & 11 & 11 & 1 & 1 & A014RE1Q156NBEA & Inv:Inventories & $\begin{array}{l}\text { Shares of GDP: gross private domestic invest- } \\
\text { ment: change in private inventories (percent) }\end{array}$ \\
\hline 12 & 12 & 12 & 5 & 0 & GCEC1 & Gov.Spending & $\begin{array}{l}\text { Real government consumption expenditures } \\
\text { and gross investment (billions of chained } 2012 \\
\text { dollars) }\end{array}$ \\
\hline 16 & 16 & 16 & 5 & 1 & EXPGSC1 & Exports & $\begin{array}{l}\text { Real exports of goods and services, } 3 \text { decimal } \\
\text { (billions of chained } 2012 \text { dollars) }\end{array}$ \\
\hline 17 & 17 & 17 & 5 & 1 & IMPGSC1 & Imports & $\begin{array}{l}\text { Real imports of goods and services, } 3 \text { decimal } \\
\text { (billions of chained } 2012 \text { dollars) }\end{array}$ \\
\hline 18 & 18 & 18 & 5 & 0 & DPIC96 & Disp-Income & $\begin{array}{l}\text { Real disposable personal income (billions of } \\
\text { chained } 2012 \text { dollars) }\end{array}$ \\
\hline 19 & 19 & 19 & 5 & 0 & OUTNFB & Ouput:NFB & $\begin{array}{l}\text { Nonfarm business sector: real output (index: } \\
2009=100 \text { ) }\end{array}$ \\
\hline 20 & 20 & 20 & 5 & 0 & OUTBS & Output:Bus & Business sector: real output (index: $2009=100$ ) \\
\hline 21 & 21 & 21 & 5 & 0 & OUTMS & Output:Manuf & $\begin{array}{l}\text { Manufacturing sector: real output (index: } \\
2009=100 \text { ) }\end{array}$ \\
\hline 22 & 190 & NA & 2 & 0 & B020RE1Q156NBEA & & $\begin{array}{l}\text { Shares of GDP: exports of goods and services } \\
\text { (percent) }\end{array}$ \\
\hline 23 & 191 & NA & 2 & 0 & B021RE1Q156NBEA & & $\begin{array}{l}\text { Shares of GDP: imports of goods and services } \\
\text { (percent) }\end{array}$ \\
\hline
\end{tabular}




\section{McCracken and $\mathbf{~ g g}$}

Table A1B

Group 2: Industrial Production (IP)

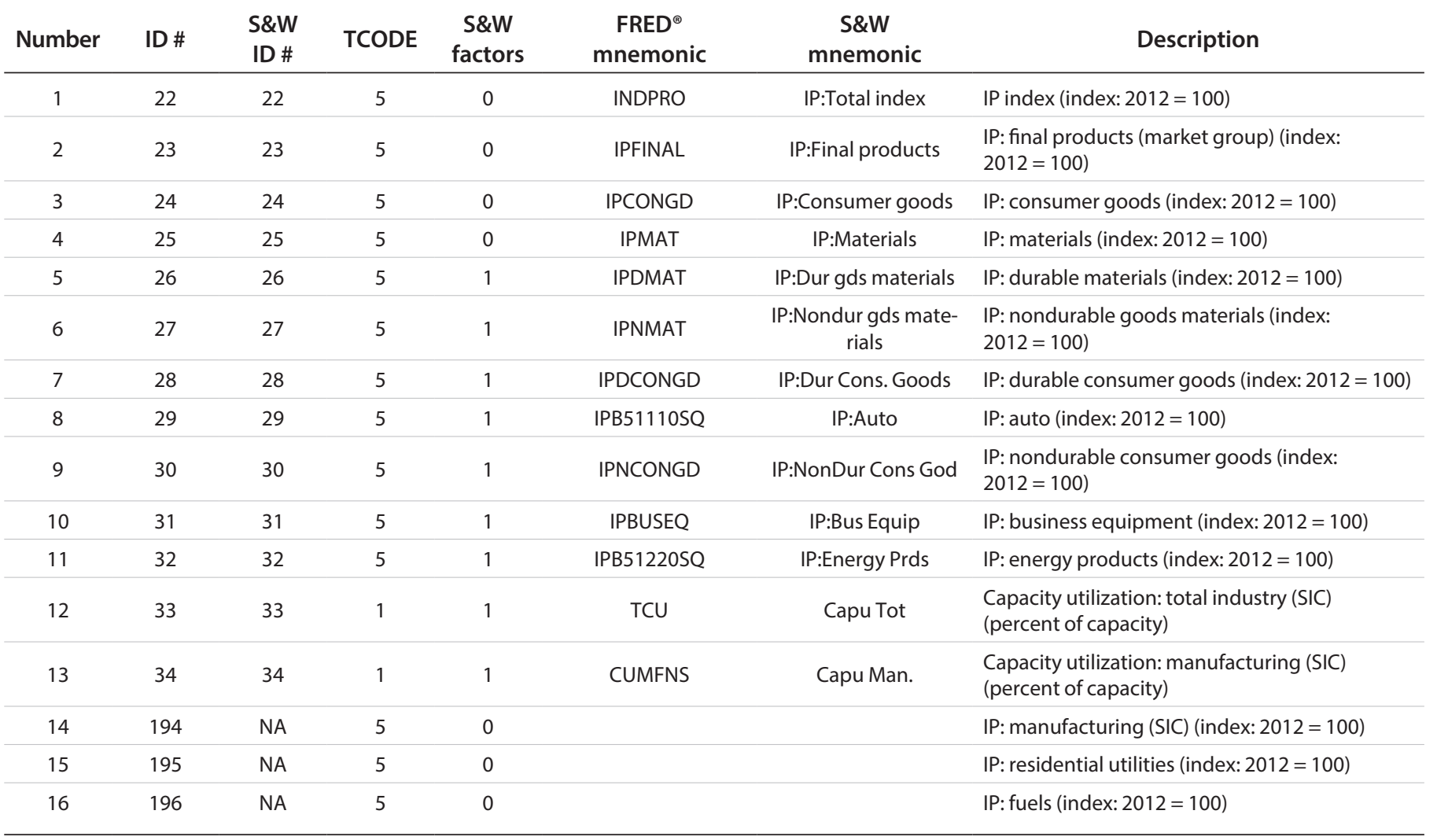


Table A1C

Group 3: Employment and Unemployment

\begin{tabular}{|c|c|c|c|c|c|c|c|}
\hline Number & ID \# & $\begin{array}{l}\text { S\&W } \\
\text { ID \# }\end{array}$ & TCODE & $\begin{array}{c}\text { S\&W } \\
\text { factors }\end{array}$ & $\begin{array}{l}\text { FRED }^{\circledR} \\
\text { mnemonic }\end{array}$ & $\begin{array}{l}\text { S\&W } \\
\text { mnemonic }\end{array}$ & Description \\
\hline 1 & 35 & 35 & 5 & 0 & PAYEMS & Emp:Nonfarm & $\begin{array}{l}\text { All employees: total nonfarm (thousands of } \\
\text { persons) }\end{array}$ \\
\hline 2 & 36 & 36 & 5 & 0 & USPRIV & Emp:Private & $\begin{array}{l}\text { All employees: total private industries } \\
\text { (thousands of persons) }\end{array}$ \\
\hline 3 & 37 & 37 & 5 & 0 & MANEMP & Emp:mfg & $\begin{array}{l}\text { All employees: manufacturing (thousands of } \\
\text { persons) }\end{array}$ \\
\hline 5 & 39 & 39 & 5 & 0 & USGOOD & Emp:Goods & $\begin{array}{l}\text { All employees: goods-producing industries } \\
\text { (thousands of persons) }\end{array}$ \\
\hline 6 & 40 & 40 & 5 & 1 & DMANEMP & Emp:DurGoods & $\begin{array}{l}\text { All employees: durable goods (thousands of } \\
\text { persons) }\end{array}$ \\
\hline 9 & 43 & 43 & 5 & 1 & USEHS & Emp:Edu\&Health & $\begin{array}{l}\text { All employees: education and health services } \\
\text { (thousands of persons) }\end{array}$ \\
\hline 10 & 44 & 44 & 5 & 1 & USFIRE & Emp:Finance & $\begin{array}{l}\text { All employees: financial activities (thousands } \\
\text { of persons) }\end{array}$ \\
\hline 11 & 45 & 45 & 5 & 1 & USINFO & Emp:Infor & $\begin{array}{l}\text { All employees: information services (thousands } \\
\text { of persons) }\end{array}$ \\
\hline 12 & 46 & 46 & 5 & 1 & USPBS & Emp:Bus Serv & $\begin{array}{l}\text { All employees: professional and business } \\
\text { services (thousands of persons) }\end{array}$ \\
\hline 13 & 47 & 47 & 5 & 1 & USLAH & Emp:Leisure & $\begin{array}{l}\text { All employees: leisure and hospitality } \\
\text { (thousands of persons) }\end{array}$ \\
\hline 17 & 51 & 51 & 5 & 0 & USGOVT & Emp:Gov & $\begin{array}{l}\text { All employees: government (thousands of } \\
\text { persons) }\end{array}$ \\
\hline 18 & 52 & 52 & 5 & 1 & USTRADE & Emp:Retail & $\begin{array}{l}\text { All employees: retail trade (thousands of } \\
\text { persons) }\end{array}$ \\
\hline 19 & 53 & 53 & 5 & 1 & USWTRADE & Emp:Wholesal & $\begin{array}{l}\text { All employees: wholesale trade (thousands of } \\
\text { persons) }\end{array}$ \\
\hline 20 & 54 & 54 & 5 & 1 & CES9091000001 & Emp:Gov(Fed) & $\begin{array}{l}\text { All employees: government: federal (thousands } \\
\text { of persons) }\end{array}$ \\
\hline 21 & 55 & 55 & 5 & 1 & CES9092000001 & Emp:Gov (State) & $\begin{array}{l}\text { All employees: government: state government } \\
\text { (thousands of persons) }\end{array}$ \\
\hline 22 & 56 & 56 & 5 & 1 & CES9093000001 & Emp:Gov (Local) & $\begin{array}{l}\text { All employees: government: local government } \\
\text { (thousands of persons) }\end{array}$ \\
\hline 23 & 57 & 57 & 5 & 0 & CE16OV & Emp:Total (HHSurve) & Civilian employment (thousands of persons) \\
\hline 24 & 58 & 58 & 2 & 0 & CIVPART & LF Part Rate & Civilian labor force participation rate (percent) \\
\hline 25 & 59 & 59 & 2 & 0 & UNRATE & Unemp Rate & Civilian unemployment rate (percent) \\
\hline
\end{tabular}


Table A1C, cont'd

\section{Group 3: Employment and Unemployment}

\begin{tabular}{|c|c|c|c|c|c|c|c|}
\hline Number & ID \# & $\begin{array}{l}\text { S\&W } \\
\text { ID \# }\end{array}$ & TCODE & $\begin{array}{c}\text { S\&W } \\
\text { factors }\end{array}$ & $\begin{array}{l}\text { FRED }^{\circledR} \\
\text { mnemonic }\end{array}$ & $\begin{array}{l}\text { S\&W } \\
\text { mnemonic }\end{array}$ & Description \\
\hline 26 & 60 & 60 & 2 & 0 & UNRATESTX & Urate_ST & $\begin{array}{l}\text { Unemployment rate for less than } 27 \text { weeks of } \\
\text { unemployment (percent) }\end{array}$ \\
\hline 27 & 61 & 61 & 2 & 0 & UNRATELTX & Urate_LT & $\begin{array}{l}\text { Unemployment rate for more than } 27 \text { weeks of } \\
\text { unemployment (percent) }\end{array}$ \\
\hline 28 & 62 & 62 & 2 & 1 & LNS14000012 & Urate:Age16-19 & Unemployment rate: ages 16 to 19 (percent) \\
\hline 29 & 63 & 63 & 2 & 1 & LNS14000025 & Urate:Age >20 Men & $\begin{array}{l}\text { Unemployment rate: age } 20 \text { and over, men } \\
\text { (percent) }\end{array}$ \\
\hline 30 & 64 & 64 & 2 & 1 & LNS14000026 & $\begin{array}{l}\text { Urate:Age }>20 \\
\text { Women }\end{array}$ & $\begin{array}{l}\text { Unemployment rate: age } 20 \text { and over, women } \\
\text { (percent) }\end{array}$ \\
\hline 31 & 65 & 65 & 5 & 1 & UEMPLT5 & U:Dur $<5$ wks & $\begin{array}{l}\text { Number of civilians unemployed less than } \\
5 \text { weeks (thousands of persons) }\end{array}$ \\
\hline 32 & 66 & 66 & 5 & 1 & UEMP5TO14 & U:Dur5-14wks & $\begin{array}{l}\text { Number of civilians unemployed } 5 \text { to } 14 \text { weeks } \\
\text { (thousands of persons) }\end{array}$ \\
\hline 33 & 67 & 67 & 5 & 1 & UEMP15T26 & U:dur>15-26wks & $\begin{array}{l}\text { Number of civilians unemployed } 15 \text { to } 26 \\
\text { weeks (thousands of persons) }\end{array}$ \\
\hline 34 & 68 & 68 & 5 & 1 & UEMP27OV & U:Dur $>27 w k s$ & $\begin{array}{l}\text { Number of civilians unemployed } 27 \text { weeks or } \\
\text { over (thousands of persons) }\end{array}$ \\
\hline 35 & 69 & 69 & 5 & 1 & LNS13023621 & U:Job losers & $\begin{array}{l}\text { Unemployment level: job losers (thousands of } \\
\text { persons) }\end{array}$ \\
\hline 36 & 70 & 70 & 5 & 1 & LNS13023557 & U:LF Reenty & $\begin{array}{l}\text { Unemployment level: reentrants to labor force } \\
\text { (thousands of persons) }\end{array}$ \\
\hline 37 & 71 & 71 & 5 & 1 & LNS13023705 & U:Job Leavers & $\begin{array}{l}\text { Unemployment level: job leavers (thousands } \\
\text { of persons) }\end{array}$ \\
\hline 38 & 72 & 72 & 5 & 1 & LNS13023569 & U:New Entrants & $\begin{array}{l}\text { Unemployment level: new entrants (thousands } \\
\text { of persons) }\end{array}$ \\
\hline 39 & 73 & 73 & 5 & 1 & LNS12032194 & Emp:SlackWk & $\begin{array}{l}\text { Employment level: part-time for economic } \\
\text { reasons, all industries (thousands of persons) }\end{array}$ \\
\hline 40 & 74 & 74 & 5 & 0 & HOABS & EmpHrs:Bus Sec & $\begin{array}{l}\text { Business sector: hours of all persons (index: } \\
2009=100 \text { ) }\end{array}$ \\
\hline 41 & 75 & 75 & 5 & 0 & HOAMS & EmpHrs:mfg & $\begin{array}{l}\text { Manufacturing sector: hours of all persons } \\
\text { (index: } 2009=100 \text { ) }\end{array}$ \\
\hline 42 & 76 & 76 & 5 & 0 & HOANBS & EmpHrs:nfb & $\begin{array}{l}\text { Nonfarm business sector: hours of all persons } \\
\text { (index: } 2009=100 \text { ) }\end{array}$ \\
\hline 43 & 77 & 77 & 1 & 1 & AWHMAN & AWH Man & $\begin{array}{l}\text { Average weekly hours of production and non- } \\
\text { supervisory employees: manufacturing (hours) }\end{array}$ \\
\hline 44 & 78 & 78 & 2 & 1 & AWHNONAG & AWH Privat & $\begin{array}{l}\text { Average weekly hours of production and non- } \\
\text { supervisory employees: total private (hours) }\end{array}$ \\
\hline 45 & 79 & 79 & 2 & 1 & AWOTMAN & AWH Overtime & $\begin{array}{l}\text { Average weekly overtime hours of production } \\
\text { and nonsupervisory employees: manufacturing } \\
\text { (hours) }\end{array}$ \\
\hline 46 & 80 & 80 & 1 & 0 & HWlx & HelpWnted & Help-wanted index \\
\hline 47 & 197 & NA & 2 & 0 & UEMPMEAN & & $\begin{array}{l}\text { Average (mean) duration of unemployment } \\
\text { (weeks) }\end{array}$ \\
\hline 48 & 198 & NA & 2 & 0 & CES0600000007 & & $\begin{array}{l}\text { Average weekly hours of production and non- } \\
\text { supervisory employees: goods producing }\end{array}$ \\
\hline 49 & 220 & NA & 2 & 0 & HWIURATIOx & & Ratio of help wanted to number unemployed \\
\hline 50 & 221 & NA & 5 & 0 & CLAIMSx & & Initial claims \\
\hline
\end{tabular}


Table A1D

\section{Group 4: Housing}

\begin{tabular}{|c|c|c|c|c|c|c|c|}
\hline Number & ID \# & $\begin{array}{l}\text { S\&W } \\
\text { ID \# }\end{array}$ & TCODE & $\begin{array}{c}\text { S\&W } \\
\text { factors }\end{array}$ & $\begin{array}{c}\text { FRED }^{\circledR} \\
\text { mnemonic }\end{array}$ & $\begin{array}{c}\text { S\&W } \\
\text { mnemonic }\end{array}$ & Description \\
\hline 1 & 81 & 81 & 5 & 0 & HOUST & Hstarts & $\begin{array}{l}\text { Housing starts: total: new privately owned } \\
\text { housing units started (thousands of units) }\end{array}$ \\
\hline 2 & 82 & 82 & 5 & 0 & HOUST5F & Hstarts $>5$ units & $\begin{array}{l}\text { Privately owned housing starts: } 5 \text {-unit structures } \\
\text { or more (thousands of units) }\end{array}$ \\
\hline 3 & 83 & 83 & 5 & 1 & PERMIT & Hpermits & $\begin{array}{l}\text { New private housing units authorized by } \\
\text { building permits (thousands of units) }\end{array}$ \\
\hline 5 & 85 & 85 & 5 & 1 & HOUSTNE & Hstarts:NE & $\begin{array}{l}\text { Housing starts in Northeast census region } \\
\text { (thousands of units) }\end{array}$ \\
\hline 6 & 86 & 86 & 5 & 1 & HOUSTS & Hstarts:S & $\begin{array}{l}\text { Housing starts in South census region } \\
\text { (thousands of units) }\end{array}$ \\
\hline 9 & 180 & 191 & 5 & 1 & SPCS10RSA & Real CS_10 & $\begin{array}{l}\text { S\&P/Case-Shiller 10-City Composite Home Price } \\
\text { Index (index: January } 2000=100 \text { ) }\end{array}$ \\
\hline 10 & 181 & 192 & 5 & 1 & SPCS20RSA & Real CS_20 & $\begin{array}{l}\text { S\&P/Case-Shiller 20-City Composite Home Price } \\
\text { Index (index: January } 2000=100 \text { ) }\end{array}$ \\
\hline 11 & 227 & NA & 5 & 0 & PERMITNE & & $\begin{array}{l}\text { New private housing units authorized by } \\
\text { building permits in the Northeast census } \\
\text { region (thousands, SAAR) }\end{array}$ \\
\hline 12 & 228 & NA & 5 & 0 & PERMITMW & & $\begin{array}{l}\text { New private housing units authorized by } \\
\text { building permits in the Midwest census region } \\
\text { (thousands, SAAR) }\end{array}$ \\
\hline
\end{tabular}

NOTE: SAAR, seasonally adjusted annual rate. 


\section{McCracken and $\mathbf{~ g g}$}

Table A1E

Group 5: Inventories, Orders, and Sales

\begin{tabular}{|c|c|c|c|c|c|c|c|}
\hline Number & ID \# & $\begin{array}{l}\text { S\&W } \\
\text { ID \# }\end{array}$ & TCODE & $\begin{array}{c}\text { S\&W } \\
\text { factors }\end{array}$ & $\begin{array}{c}\text { FRED }^{\circledR} \\
\text { mnemonic }\end{array}$ & $\begin{array}{c}\text { S\&W } \\
\text { mnemonic }\end{array}$ & Description \\
\hline 1 & 88 & 89 & 5 & 0 & CMRMTSPLX & MT Sales & $\begin{array}{l}\text { Real manufacturing and trade industries sales } \\
\text { (millions of chained } 2012 \text { dollars) }\end{array}$ \\
\hline 2 & 89 & 90 & 5 & 1 & RSAFS $x$ & Ret. Sale & $\begin{array}{l}\text { Real retail and food services sales (millions of } \\
\text { chained } 2012 \text { dollars), deflated by core PCE }\end{array}$ \\
\hline 3 & 90 & 91 & 5 & 1 & AMDMNOx & Orders(DurMfg) & $\begin{array}{l}\text { Real manufacturers' new orders: durable goods } \\
\text { (millions of } 2012 \text { dollars), deflated by core PCE }\end{array}$ \\
\hline 5 & 92 & 93 & 5 & 1 & AMDMUOx & UnfOrders(DurGds) & $\begin{array}{l}\text { Real value of manufacturers' unfilled orders for } \\
\text { durable goods industries (millions of } 2012 \\
\text { dollars), deflated by core PCE }\end{array}$ \\
\hline 7 & 94 & 96 & 5 & 1 & INVCQRMTSPL & MT Invent & $\begin{array}{l}\text { Real manufacturing and trade inventories } \\
\text { (millions of } 2012 \text { dollars) }\end{array}$ \\
\hline 8 & 222 & NA & 5 & 0 & BUSINVx & & Total business inventories (millions of dollars) \\
\hline 9 & 223 & NA & 2 & 0 & ISRATIOx & & Total business: inventories-to-sales ratio \\
\hline
\end{tabular}




\section{Table A1F}

\section{Group 6: Prices}

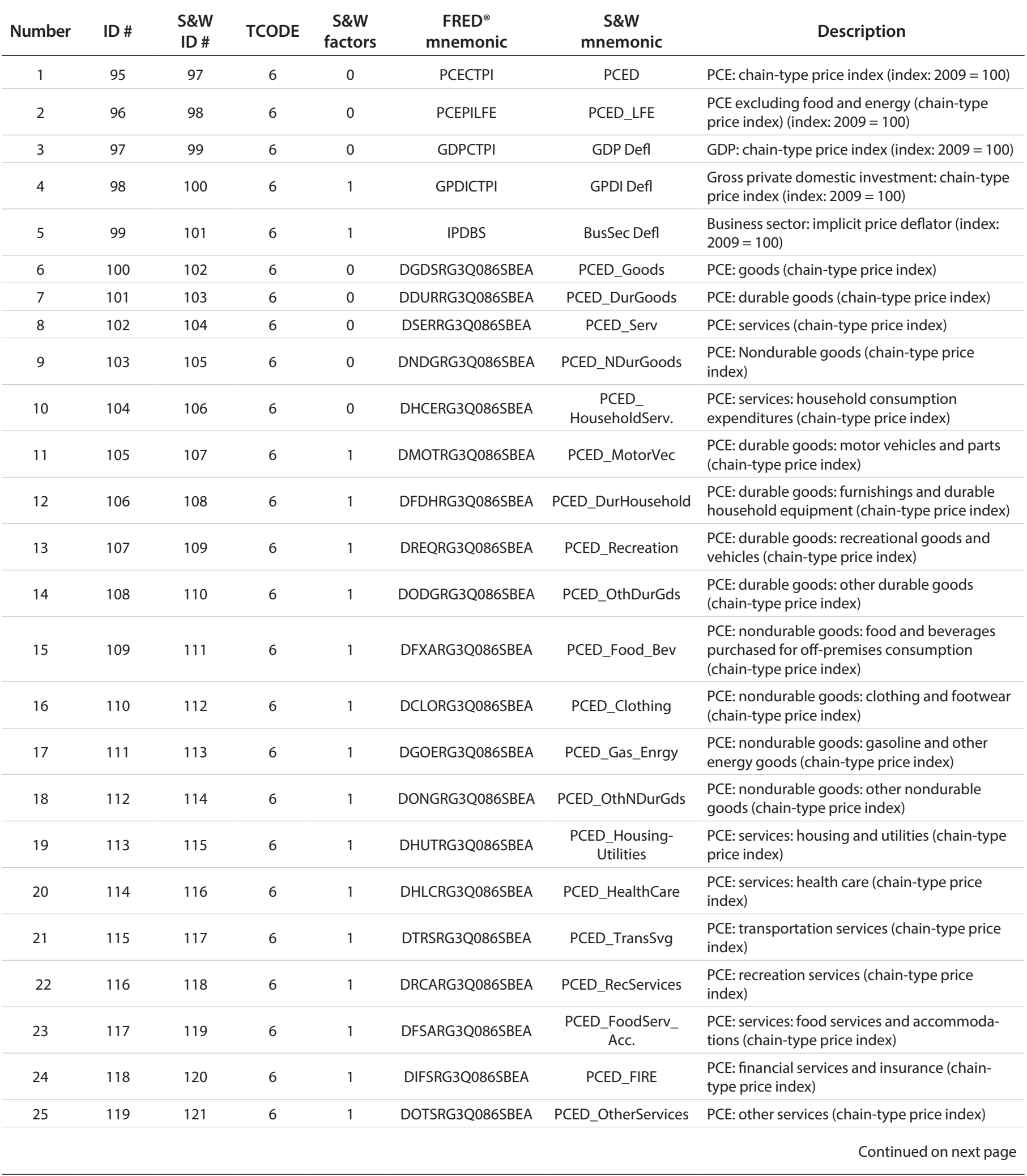


Table A1F, cont'd

\section{Group 6: Prices}

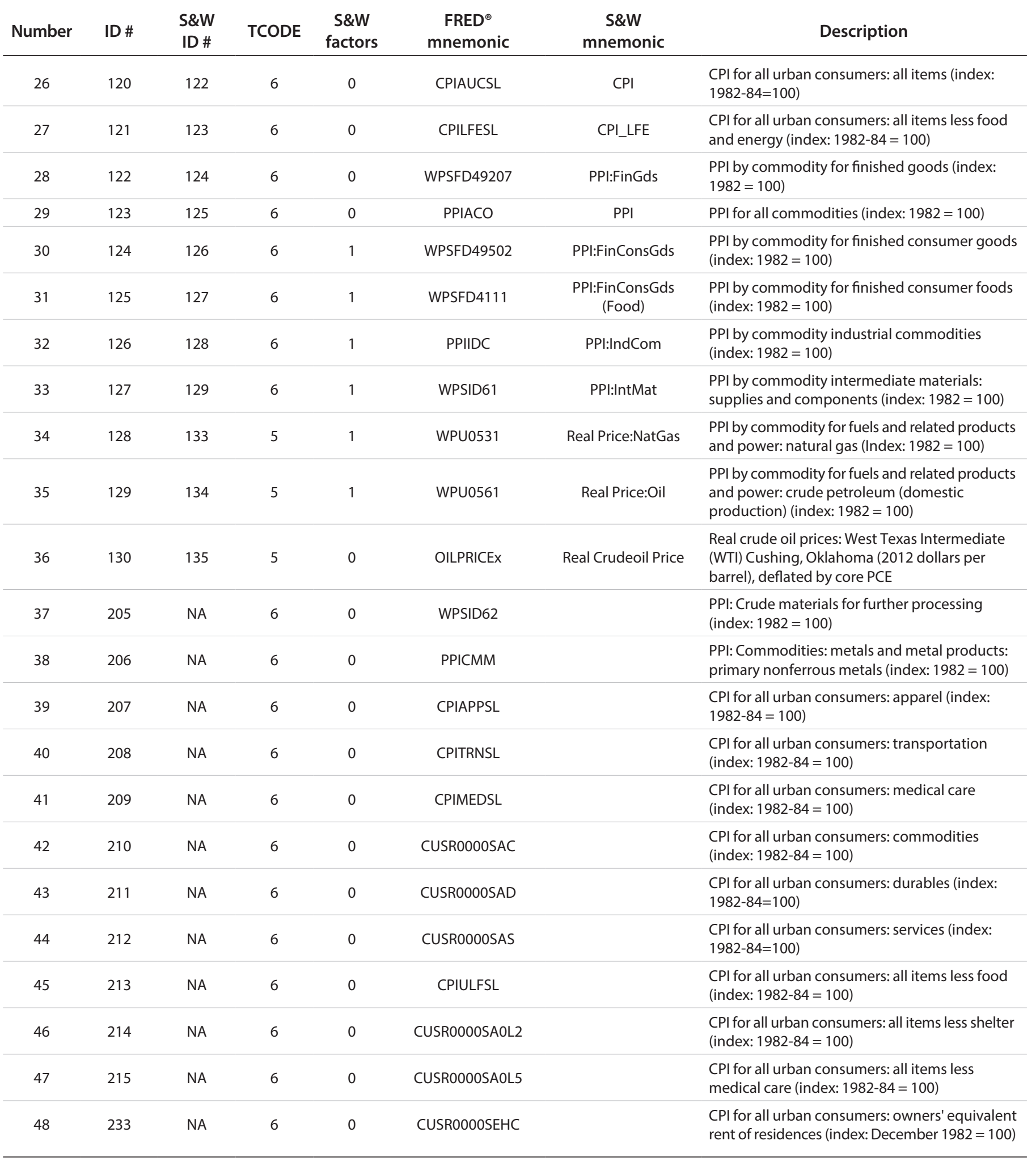


Table A1G

Group 7: Earning and Productivity

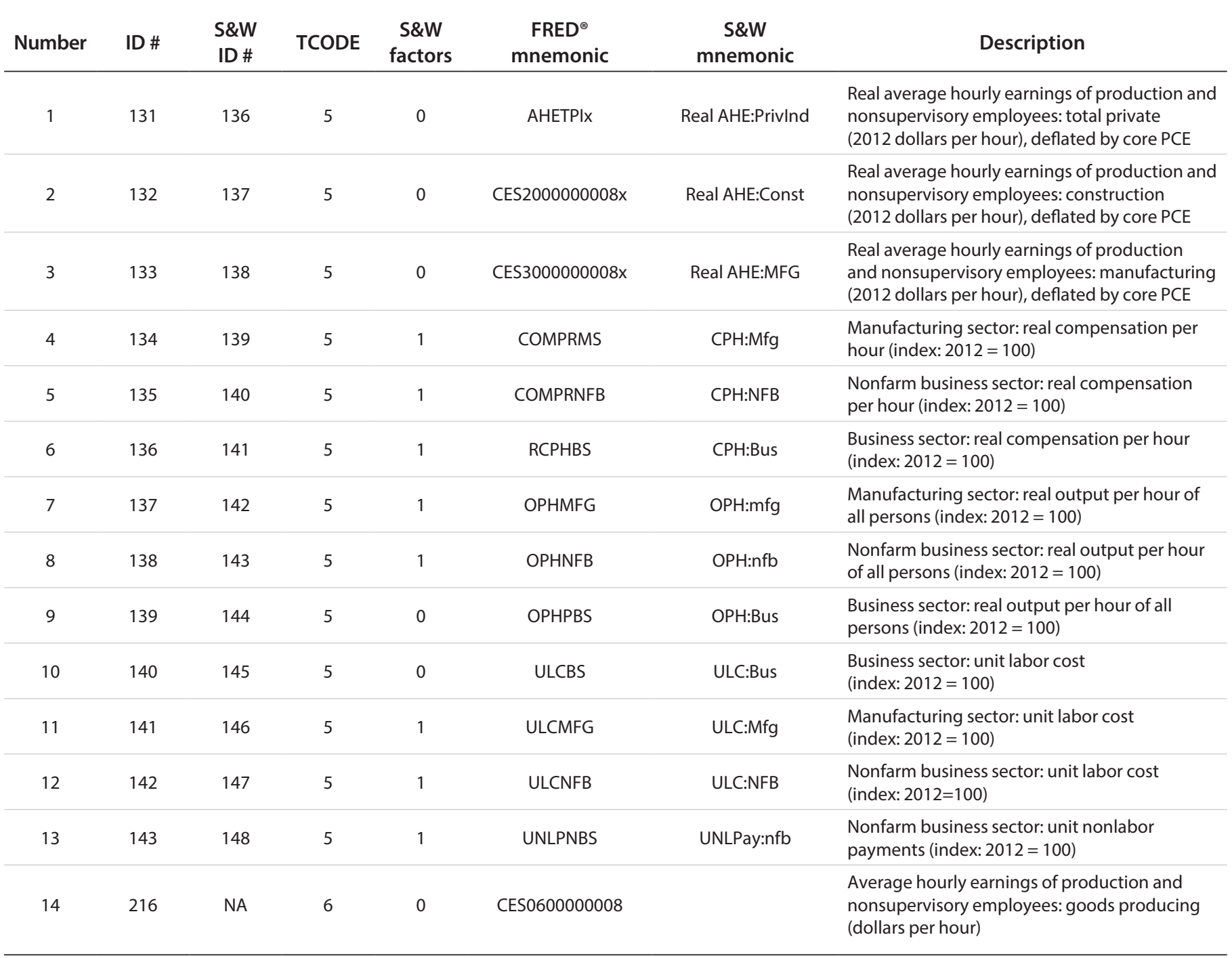




\section{McCracken and $\mathbf{~ g g}$}

\section{Table A1 H}

\section{Group 8: Interest Rates}

\begin{tabular}{|c|c|c|c|c|c|c|c|}
\hline Number & ID \# & $\begin{array}{l}\text { S\&W } \\
\text { ID \# }\end{array}$ & TCODE & $\begin{array}{l}\text { S\&W } \\
\text { factors }\end{array}$ & $\begin{array}{l}\text { FRED }^{\circledR} \\
\text { mnemonic }\end{array}$ & $\begin{array}{l}\text { S\&W } \\
\text { mnemonic }\end{array}$ & Description \\
\hline 1 & 144 & 149 & 2 & 1 & FEDFUNDS & FedFunds & Effective federal funds rate (percent) \\
\hline 2 & 145 & 150 & 2 & 1 & TB3MS & TB-3Mth & $\begin{array}{l}\text { 3-Month Treasury bill (T-bill): secondary market } \\
\text { rate (percent) }\end{array}$ \\
\hline 3 & 146 & 151 & 2 & 0 & TB6MS & TM-6MTH & 6-Month T-bill: secondary market rate (percent) \\
\hline 4 & 147 & 153 & 2 & 0 & GS1 & TB-1YR & 1-Year Treasury constant maturity rate (percent) \\
\hline 5 & 148 & 154 & 2 & 0 & GS10 & TB-10YR & 10-Year Treasury constant maturity rate (percent) \\
\hline 6 & 149 & 155 & 2 & 0 & MORTGAGE30US & Mort-30Yr & 30-Year conventional mortgage rate (percent) \\
\hline 7 & 150 & 156 & 2 & 0 & AAA & AAA Bond & $\begin{array}{l}\text { Moody's Seasoned Aaa Corporate Bond Yield } \\
\text { (percent) }\end{array}$ \\
\hline 8 & 151 & 157 & 2 & 0 & BAA & BAA Bond & $\begin{array}{l}\text { Moody's Seasoned Baa Corporate Bond Yield }{ }^{\odot} \\
\text { (percent) }\end{array}$ \\
\hline 9 & 152 & 158 & 1 & 1 & BAA10YM & BAA_GS10 & $\begin{array}{l}\text { Moody's Seasoned Baa Corporate Bond Yield } \\
\text { relative to yield on 10-year Treasury constant } \\
\text { maturity (percent) }\end{array}$ \\
\hline 10 & 153 & 159 & 1 & 1 & MORTG10YRx & MRTG_GS10 & $\begin{array}{l}\text { 30-Year conventional mortgage rate relative to } \\
10 \text {-year Treasury constant maturity (percent) }\end{array}$ \\
\hline 11 & 154 & 160 & 1 & 1 & TB6M3Mx & tb6m_tb3m & $\begin{array}{l}\text { 6-Month T-bill minus 3-month T-bill, secondary } \\
\text { market (percent) }\end{array}$ \\
\hline 12 & 155 & 161 & 1 & 1 & GS1TB3Mx & GS1_tb3m & $\begin{array}{l}\text { 1-Year Treasury constant maturity minus } \\
\text { 3-month T-bill, secondary market (percent) }\end{array}$ \\
\hline 13 & 156 & 162 & 1 & 1 & GS10TB3Mx & GS10_tb3m & $\begin{array}{l}\text { 10-Year Treasury constant maturity minus } \\
\text { 3-month T-bill, secondary market (percent) }\end{array}$ \\
\hline 14 & 157 & 163 & 1 & 1 & CPF3МТВ3Мх & CP_Tbill Spread & $\begin{array}{l}\text { 3-Month commercial paper minus 3-month } \\
\text { T-bill, secondary market (percent) }\end{array}$ \\
\hline 15 & 201 & NA & 2 & 0 & GS5 & & 5-Year Treasury constant maturity rate \\
\hline 16 & 202 & NA & 1 & 0 & TB3SMFFM & & $\begin{array}{l}\text { 3-Month Treasury constant maturity minus } \\
\text { federal funds rate }\end{array}$ \\
\hline 17 & 203 & NA & 1 & 0 & T5YFFM & & $\begin{array}{l}5 \text {-Year Treasury constant maturity minus } \\
\text { federal funds rate }\end{array}$ \\
\hline 18 & 204 & NA & 1 & 0 & AAAFFM & & $\begin{array}{l}\text { Moody's Seasoned Aaa Corporate Bond minus } \\
\text { federal funds rate }\end{array}$ \\
\hline 19 & 225 & NA & 2 & 0 & СР3M & & 3-Month AA financial commercial paper rate \\
\hline 20 & 226 & NA & 1 & 0 & COMPAPFF & & $\begin{array}{l}\text { 3-Month commercial paper minus federal } \\
\text { funds rate }\end{array}$ \\
\hline
\end{tabular}




\section{Table A1I}

\section{Group 9: Money and Credit}

\begin{tabular}{|c|c|c|c|c|c|c|c|}
\hline Number & ID \# & $\begin{array}{l}\text { S\&W } \\
\text { ID \# }\end{array}$ & TCODE & $\begin{array}{c}\text { S\&W } \\
\text { factors }\end{array}$ & $\begin{array}{c}\text { FRED }^{\circledR} \\
\text { mnemonic }\end{array}$ & $\begin{array}{c}\text { S\&W } \\
\text { mnemonic }\end{array}$ & Description \\
\hline 1 & 158 & 167 & 5 & 0 & AMBSLREAL & Real Mbase & $\begin{array}{l}\text { St. Louis adjusted monetary base (millions of } \\
\text { 1982-84 dollars), deflated by CPI }\end{array}$ \\
\hline 2 & 159 & 168 & 5 & 0 & IMFSLX & Real InsMMF & $\begin{array}{l}\text { Real institutional money funds (billions of } 2012 \\
\text { dollars), deflated by core PCE }\end{array}$ \\
\hline 3 & 160 & 169 & 5 & 0 & M1REAL & Real m1 & $\begin{array}{l}\text { Real M1 money stock (billions of 1982-84 } \\
\text { dollars), deflated by CPI }\end{array}$ \\
\hline 4 & 161 & 170 & 5 & 0 & M2REAL & Real m2 & $\begin{array}{l}\text { Real M2 money stock (billions of 1982-84 dollars), } \\
\text { deflated by CPI }\end{array}$ \\
\hline 5 & 162 & 171 & 5 & 0 & MZMREAL & Real mzm & $\begin{array}{l}\text { Real MZM money stock (billions of 1982-84 } \\
\text { dollars), deflated by CPI }\end{array}$ \\
\hline 6 & 163 & 172 & 5 & 1 & BUSLOANSx & Real C\&Lloand & $\begin{array}{l}\text { Real commercial and industrial loans, all } \\
\text { commercial banks (billions of } 2012 \text { dollars), } \\
\text { deflated by core PCE }\end{array}$ \\
\hline 8 & 165 & 174 & 5 & 1 & NONREVSLX & Real NonRevCredit & $\begin{array}{l}\text { Total real nonrevolving credit owned and } \\
\text { securitized, outstanding (billions of } 2012 \\
\text { dollars), deflated by core PCE }\end{array}$ \\
\hline 9 & 166 & 175 & 5 & 1 & REALLNx & Real LoansRealEst & $\begin{array}{l}\text { Real real estate loans, all commercial banks } \\
\text { (billions of } 2012 \text { dollars), deflated by core PCE }\end{array}$ \\
\hline 10 & 167 & 176 & 5 & 1 & REVOLSLX & Real RevolvCredit & $\begin{array}{l}\text { Total real revolving credit owned and } \\
\text { securitized, outstanding (billions of } 2012 \\
\text { dollars), deflated by core PCE }\end{array}$ \\
\hline 11 & 168 & 177 & 5 & 0 & TOTALSLX & Real ConsuCred & $\begin{array}{l}\text { Total consumer credit outstanding (billions of } \\
2012 \text { dollars), deflated by core PCE }\end{array}$ \\
\hline 15 & 217 & NA & 6 & 0 & DTCOLNVHFNM & & $\begin{array}{l}\text { Consumer motor vehicle loans outstanding } \\
\text { owned by finance companies (millions of } \\
\text { dollars) }\end{array}$ \\
\hline 16 & 218 & NA & 6 & 0 & DTCTHFNM & & $\begin{array}{l}\text { Total consumer loans and leases outstanding } \\
\text { owned and securitized by finance companies } \\
\text { (millions of dollars) }\end{array}$ \\
\hline 17 & 219 & NA & 6 & 0 & INVEST & & $\begin{array}{l}\text { Securities in bank credit at all commercial } \\
\text { banks (billions of dollars) }\end{array}$ \\
\hline
\end{tabular}




\section{McCracken and $\mathbf{N g}$}

\section{Table A $1 \mathrm{~J}$}

\section{Group 10: Household Balance Sheets}

\begin{tabular}{|c|c|c|c|c|c|c|c|}
\hline Number & ID \# & $\begin{array}{l}\text { S\&W } \\
\text { ID \# }\end{array}$ & TCODE & $\begin{array}{c}\text { S\&W } \\
\text { factors }\end{array}$ & $\begin{array}{l}\text { FRED }^{\circledR} \\
\text { mnemonic }\end{array}$ & $\begin{array}{l}\text { S\&W } \\
\text { mnemonic }\end{array}$ & Description \\
\hline 1 & 170 & 179 & 5 & 0 & TABSHNOx & Real HHW:TASA & $\begin{array}{l}\text { Real total assets of households and nonprofit } \\
\text { organizations (billions of } 2012 \text { dollars), deflated } \\
\text { by core PCE }\end{array}$ \\
\hline 2 & 171 & 181 & 5 & 1 & TLBSHNOx & Real HHW:LiabSA & $\begin{array}{l}\text { Real total liabilities of households and non- } \\
\text { profit organizations (billions of } 2012 \text { dollars), } \\
\text { deflated by core PCE }\end{array}$ \\
\hline 3 & 172 & 182 & 5 & 0 & LIABPIx & liab_PDISA & $\begin{array}{l}\text { Liabilities of households and nonprofit organi- } \\
\text { zations relative to personal disposable income } \\
\text { (percent) }\end{array}$ \\
\hline 4 & 173 & 183 & 5 & 1 & TNWBSHNOx & Real HHW:WSA & $\begin{array}{l}\text { Real net worth of households and nonprofit } \\
\text { organizations (billions of } 2012 \text { dollars), deflated } \\
\text { by core PCE }\end{array}$ \\
\hline 5 & 174 & 184 & 1 & 0 & NWPIx & W_PDISA & $\begin{array}{l}\text { Net worth of households and nonprofit organi- } \\
\text { zations relative to disposable personal income } \\
\text { (percent) }\end{array}$ \\
\hline 6 & 175 & 185 & 5 & 1 & TARESAx & Real HHW:TA_RESA & $\begin{array}{l}\text { Real assets of households and nonprofit organi- } \\
\text { zations excluding real estate assets (billions of } \\
2012 \text { dollars), deflated by core PCE }\end{array}$ \\
\hline 7 & 176 & 186 & 5 & 1 & HNOREMQ027Sx & Real HHW:RESA & $\begin{array}{l}\text { Real estate assets of households and nonprofit } \\
\text { organizations (billions of } 2012 \text { dollars), deflated } \\
\text { by core PCE }\end{array}$ \\
\hline 8 & 177 & 188 & 5 & 1 & TFAABSHNOx & Real HHW:FinSA & $\begin{array}{l}\text { Real total financial assets of households and } \\
\text { nonprofit organizations (billions of } 2012 \\
\text { dollars), deflated by core PCE }\end{array}$ \\
\hline 9 & 224 & NA & 2 & 0 & CONSPIX & & $\begin{array}{l}\text { Nonrevolving consumer credit to personal } \\
\text { income }\end{array}$ \\
\hline
\end{tabular}




\section{Table A1K}

\section{Group 11: Exchange Rates}

\begin{tabular}{|c|c|c|c|c|c|c|c|}
\hline Number & ID \# & $\begin{array}{l}\text { S\&W } \\
\text { ID \# }\end{array}$ & TCODE & $\begin{array}{c}\text { S\&W } \\
\text { factors }\end{array}$ & $\begin{array}{l}\text { FRED }^{\circledR} \\
\text { mnemonic }\end{array}$ & $\begin{array}{l}\text { S\&W } \\
\text { mnemonic }\end{array}$ & Description \\
\hline 1 & 182 & 193 & 5 & 1 & TWEXMMTH & Ex rate:major & $\begin{array}{l}\text { Trade weighted U.S. dollar index: major } \\
\text { currencies (index: March } 1973=100 \text { ) }\end{array}$ \\
\hline 2 & 183 & 194 & 5 & 1 & EXUSEU & Ex rate:Euro & $\begin{array}{l}\text { U.S./euro foreign exchange rate (U.S. dollars to } \\
\text { one euro) }\end{array}$ \\
\hline 3 & 184 & 195 & 5 & 1 & EXSZUSx & Ex rate:Switz & Switzerland/U.S. foreign exchange rate \\
\hline 4 & 185 & 196 & 5 & 1 & EXJPUSX & Ex rate:Japan & Japan/U.S. foreign exchange rate \\
\hline 5 & 186 & 197 & 5 & 1 & EXUSUKx & Ex rate:UK & U.S./U.K. foreign exchange rate \\
\hline 6 & 187 & 198 & 5 & 1 & EXCAUSx & EX rate:Canada & Canada/U.S. foreign exchange rate \\
\hline
\end{tabular}

\section{Table A1L}

\section{Group 12: Other}

\begin{tabular}{cccccccc} 
Number & ID \# & $\begin{array}{c}\text { S\&W } \\
\text { ID \# }\end{array}$ & TCODE & $\begin{array}{c}\text { S\&W } \\
\text { factors }\end{array}$ & $\begin{array}{c}\text { FRED } \\
\text { mnemonic }\end{array}$ & $\begin{array}{c}\text { S\&W } \\
\text { mnemonic }\end{array}$ & Description \\
\hline 1 & 188 & 199 & 1 & 1 & UMCSENTx & Cons. Expectations & $\begin{array}{l}\text { University of Michigan: Consumer Sentiment } \\
\text { (Index 1966:Q1 = 100) }\end{array}$ \\
\hline 2 & 189 & 200 & 2 & 1 & USEPUINDXM & PolicyUncertainty & $\begin{array}{l}\text { Economic Policy Uncertainty Index for United } \\
\text { States }\end{array}$ \\
\hline
\end{tabular}

\section{Table A1M}

\section{Group 13: Stock Markets}

\begin{tabular}{|c|c|c|c|c|c|c|c|}
\hline Number & ID \# & $\begin{array}{l}\text { S\&W } \\
\text { ID \# }\end{array}$ & TCODE & $\begin{array}{l}\text { S\&W } \\
\text { factors }\end{array}$ & $\begin{array}{l}\text { FRED }^{\circledR} \\
\text { mnemonic }\end{array}$ & $\begin{array}{l}\text { S\&W } \\
\text { mnemonic }\end{array}$ & Description \\
\hline 1 & 178 & 189 & 1 & 1 & VXOCLSx & $\mathrm{VXO}$ & CBOE S\&P 100 Volatility Index: VXO \\
\hline 2 & 231 & NA & 5 & 0 & NIKKEI225 & & Nikkei stock average \\
\hline 3 & 232 & NA & 5 & 0 & NASDAQCOM & & NASDAQ composite (index: Feb. 5, $1971=100$ ) \\
\hline 4 & 245 & 180 & 5 & 0 & S\&P 500 & & S\&P's Common Stock Price Index: composite \\
\hline 5 & 246 & NA & 5 & 0 & S\&P: indust & & S\&P's Common Stock Price Index: industrials \\
\hline 6 & 247 & NA & 2 & 0 & S\&P div yield & & S\&P's composite common stock: dividend yield \\
\hline 7 & 248 & NA & 5 & 0 & S\&P PE ratio & & $\begin{array}{l}\text { S\&P's composite common stock: price-earnings } \\
\text { ratio }\end{array}$ \\
\hline
\end{tabular}




\section{McCracken and $\mathbf{~ g g}$}

\section{Table A1N}

\section{Group 14: Non-Household Balance Sheets}

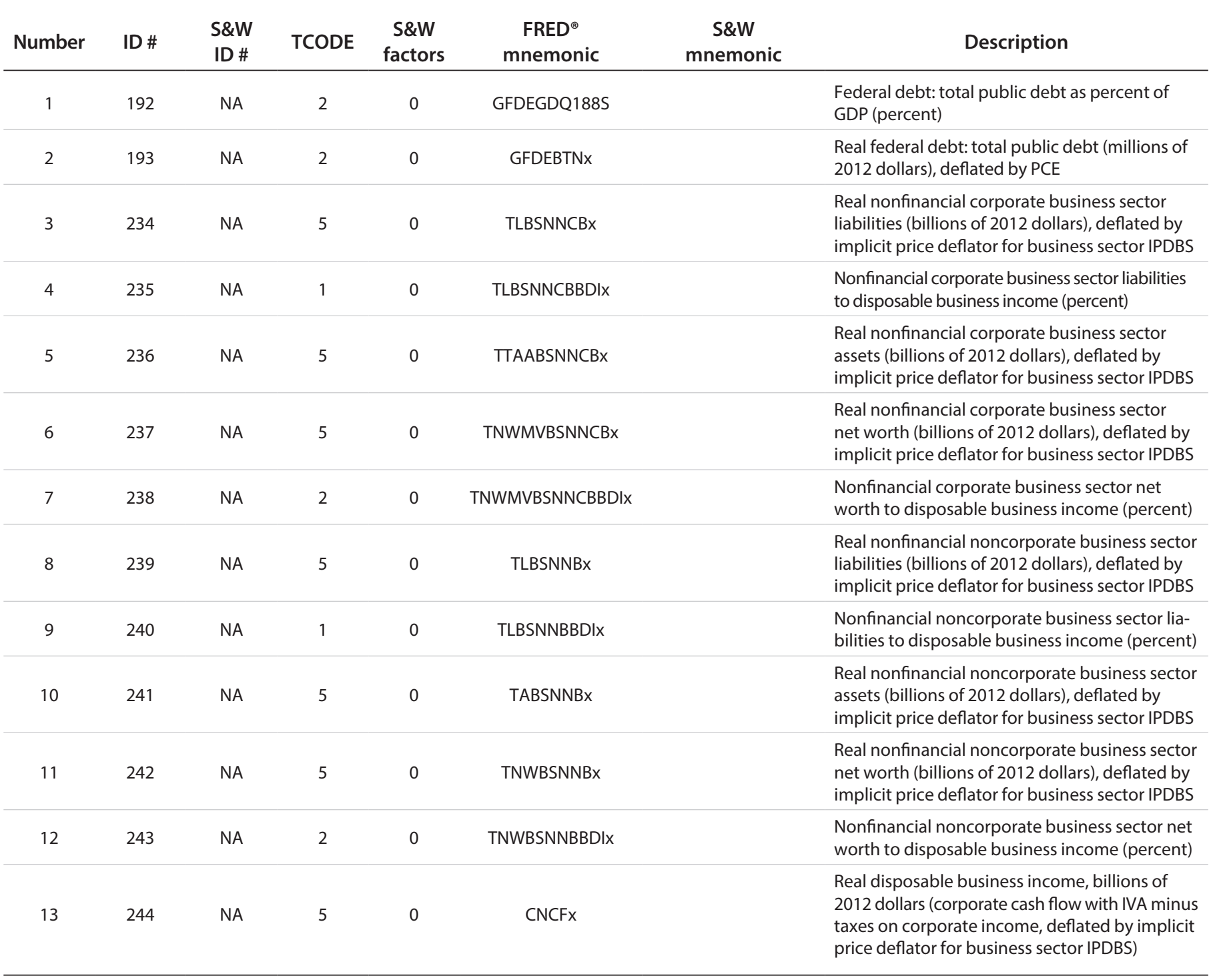




\section{NOTES}

1 FRED-QD does not contain 10 series that are in the original S\&W dataset. Using the S\&W numbering system, these are \#88 (construction contracts), \#130 (index of sensitive materials prices), \#131 (spot market price index of commodities), \#165 and \#166 (measures of credit spreads and excess bond premia, respectively, developed in Gilchrist and Zakrajsek, 2012), \#95 and \#132 (ISM index of supplier deliveries and ISM commodity price index, respectively), \#152 and \#164 (3-month eurodollar deposit rate and its spread with a 3-month T-bill, respectively), and \#187 (Dow Jones industrials index). In all but two cases, these are series not available in FRED ${ }^{\circledR}$. Three-month eurodollar deposit rates are in FRED ${ }^{\circledR}$ but are not updated on a regular basis because the source (i.e., the Organisation for Economic Co-operation and Development) does not update them regularly. The last of these, \#187, has been replaced with the S\&P 500 Industrials Index.

$\underline{2}$ Throughout we focus on factors that are $I(0)$. In contrast, Choi and Jeong (2020) provide theoretical and empirical results comparing the forecast accuracy of factors when one has the opportunity to construct them so that they are either $I(0)$ or . I(1) In the context of autoregressive models, Diebold and Kilian (2000) provide simulation evidence on a similar issue.

$\underline{3}$ The S\&P price-to-earnings (PE) ratio and dividend yield are taken from Robert Shiller's website: http://www.econ.yale.edu/ shiller/data.htm. These series are updated less consistently than the other series in the dataset. In some idiosyncratic cases, these may be missing for a longer sequence of vintages.

4 The data are currently posted on Mark Watson's website: https://www.princeton.edu/ mwatson/publi.html.

5 See Section 4 for further discussion.

$\underline{6}$ The dominant factors are almost identical when the missing values are imputed using the method in Bai and $\mathrm{Ng}$ (2019a).

$\underline{7}$ The factors have been multiplied by -1 where necessary to make the two estimates positively correlated.

$\underline{8}$ These differ from the concept of an influential observation. An observation is influential if its inclusion substantially changes the parameter estimates. See Chatterjee and Hadi (1986) and Rousseeuw and Zomeren (1990).

9 For the S\&W data, these are REVOLSL, WPU0561, PPIDC, PPITM, CES9091000001, and CONSUMER. For the subset of FRED-QD data, PPITM is replaced by WPSID61.

10 The dates associated with these outliers, many of which are recessions, also makes the exogeneity of these events questionable.

11 In unreported results we chose lag lengths based on the sequential $t$-test (Seq.t), as described in $\mathrm{Ng}$ and Perron (1995). The results were very similar to those for the MAIC, and hence we do not report them, for brevity.

12 We omit nonborrowed reserves from these figures because it is the only series with transformation code 7 . This code exists because nonborrowed reserves, which should be positive, turned negative during the Financial Crisis. This precludes the use of transformation code 5.

$\underline{13}$ In part we focus on the SIC-based factors because of our intuition on what some transformations "should" be. For example, MAIC-based tests recommend treating real GDP as I(2) in log levels. This does not strike us as reasonable.

14 In unreported work, we also considered a weaker 10 percent level of significance. For several of the variables, nearly all of the models were included in the model confidence set despite, what appeared to be, substantial differences in mean-squared errors.

\section{REFERENCES}

Angelini, G.; Bacchiocchi, E.; Caggiano G. and Fanelli L. "Uncertainty Across Volatility Regimes." Journal of Applied Econometrics, 2019, 34, pp. 437-55; https://doi.org/10.1002/jae.2672.

Bai, J. and Ng, S. "Determining the Number of Factors in Approximate Factor Models." Econometrica, 2002, 70, pp. 191-221; https://doi.org/10.1111/1468-0262.00273.

Bai, J. and Ng, S. "Matrix Completion, Counterfactuals, and Factor Analysis of Missing Data." 2019a; https://arxiv.org/abs/1910.06677. 


\section{McCracken and Ng}

Bai, J. and Ng, S. "Rank-Regularized Estimation of Approximate Factor Models." Journal of Econometrics, September 2019b, 212, pp. 78-96; https://doi.org/10.1016/j.jeconom.2019.04.021.

Barbarino, A. and Bura, E. "A Unified Framework for Dimension Reduction in Forecasting." 2017, Working Paper 2017-004, Board of Governors of the Federal Reserve System; https://doi.org/10.17016/FEDS.2017.004.

Barnichon, R. "Building a Composite Help-Wanted Index." Economic Letters, 2010, 109, pp. 175-78; https://doi.org/10.1016/j.econlet.2010.08.029.

Bauer, M.D. and Hamilton J.D. "Robust Bond Risk Premia." Review of Financial Studies, 2017, 31, pp. 399-448; https://doi.org/10.1093/rfs/hhx096.

Bernanke, B.S. and Boivin, J. "Monetary Policy in a Data-Rich Environment." Journal of Monetary Economics, 2003, 50, pp. 525-46.

Bloom, N. "The Impact of Uncertainty Shocks." Econometrica, 2009, 77, pp. 623-85; https://doi.org/10.3982/ECTA6248.

Boivin, J. and Ng, S. "Understanding and Comparing Factor-Based Forecasts." International Journal of Central Banking, 2005, 1, pp. 117-51.

Boot, T. and Nibbering, D. "Forecasting Using Random Subspace Methods." Journal of Econometrics, 2019, 209, pp. 391-406; https://doi.org/10.1016/i.j.jeconom.2019.01.009.

Campbell, S.D. "Macroeconomic Volatility, Predictability, and Uncertainity in the Great Moderation: Evidence From the Survey of Professionsl Forecasters. " Journal of Business and Economic Statistics, 2007, 25, pp. 191-200; https://doi.org/10.1198/073500106000000558.

Carrasco, M. and Rossi B. "In-Sample Inference and Forecasting in Misspecified Factor Models." Journal of Business and Economic Statistics, 2016, 34, pp. 313-38; https://doi.org/10.1080/07350015.2016.1186029.

Chatterjee, S. and Hadi, A. "Influential Observations, Leverage Points, and Outliers in Linear Regression." Statistical Science, 1986, 1, pp. 379-93; https://doi.org/10.1214/ss/1177013622.

Choi, I. and Jeong, H. "Differencing versus Non-Differencing in Factor-Based Forecasting." Journal of Applied Econometrics, September/October 2020, 35(6), pp. 728-50; https://doi.org/10.1002/jae.2777.

Coroneo, L. and Fabrizio, I. "Comparing Predictive Accuracy in Small Samples Using Fixed-Smoothing Asymptotics." Journal of Applied Econometrics, June/July 2020, 35(4), pp. 391-409; https://doi.org/10.1002/jae.2756.

Davig, T. and Hall, A.S. "Recession Forecasting Using Bayesian Classification." International Journal of Forecasting, 2019, 35, pp. 848-67; https://doi.org/10.1016/j.ijforecast.2018.08.005.

Diebold, F.X. and Kilian, L. "Unit Root Tests are Useful for Selecting Forecasting Models." Journal of Business and Economic Statistics, 2000, 18, pp. 265-73; https://doi.org/10.1080/07350015.2000.10524869.

Ellington, M.; Florackis, C. and Milas, C. "Liquidity Shocks and Real GDP Growth: Evidence from a Bayesian TimeVarying Parameter VAR." Journal of International Money and Finance, 2017, 72, pp. 93-117; https://doi.org/10.1016/j.jimonfin.2016.12.002.

Elliot, G.; Rothenberg, T.J. and Stock, J.H. "Efficient Tests for an Autoregressive Unit Root." Econometrica, 1996, 64, pp. 813-36; https://doi.org/10.2307/2171846.

Fortin-Gagnon, O.; Leroux, M.; Stevanovic, D. and Surprenant, S. "A Large Canadian Database for Macroeconomic Analysis." CIRANO Working Paper, 2018.

Gefang, D.; Koop, G. and Poon, A. "Variational Bayesian Inference in Large Vector Autoregressions with Hierarchical Shrinkage." CAMA Working Papers, 2019-08; https://doi.org/10.2139/ssrn.3321510.

Giacomini, R. and White, H. "Tests of Conditional Predictive Ability." Econometrica, 2006, 74, pp. 1545-78; https://doi.org/10.1111/j.1468-0262.2006.00718.x.

Giannone, D.; Lenza, M. and Primiceri, G.E. "Economic Predictions with Big Data: The Illusion of Sparsity." Federal Reserve Bank of New York Staff Report No. 847, 2018; https://doi.org/10.2139/ssrn.3166281.

Gilchrist, S. and Zakrajsek, E. "Credit Spreads and Business Cycle Fluctuations." American Economic Review, 2012, 102, pp. 1692-720; https://doi.org/10.1257/aer.102.4.1692. 
Gonçalves, S.; Perron, B. and Djogbenou, A. "Bootstrap Prediction Intervals for Factor Models." Journal of Business and Economic Statistics, 2017, 35, pp. 53-69; https://doi.org/10.1080/07350015.2015.1054492.

Goulet Coulombe, P.; Leroux, M.; Stevanovic, D. and Surprenant, S. "How is Machine Learning Useful for Macroeconomic Forecasting?" 2019, CIRANO Working Paper.

Hansen, P.R.; Lunde, A. and Nason, J.M. "The Model Confidence Set." Econometrica, 2011, 79, pp. 453-97; https://doi.org/10.3982/ECTA5771.

Hu, B. and Park, J.Y. "Econometric Analysis of Functional Dynamics in the Presence of Persistence." Working Paper, 2017.

Jurado, K.; Ludvigson, S.C. and Ng, S. "Measuring Uncertainty." American Economic Review, 2015, 105, pp. 1177-216; https://doi.org/10.1257/aer.20131193.

Kiefer, N.M. and Vogelsang, T.J. "A New Asymptotic Theory for Heteroskedasticity-Autocorrelation Robust Tests." Econometric Theory, 2005, 21, pp. 1130-64; https://doi.org/10.1017/S0266466605050565.

Koop, G. "Forecasting with Medium and Large Bayesian VARs." Journal of Applied Econometrics, 2013, 28, pp. 177-203; https://doi.org/10.1002/jae.1270.

Koopman, S.J. and Mesters G. "Empirical Bayes Methods for Dynamic Factor Models." Review of Economics and Statistics, 2017, 99, pp. 486-98; https://doi.org/10.1162/REST a 00614.

Kotchoni, R.; Leroux, M. and Stevanovic, D. "Macroeconomic Forecast Accuracy in a Data-Rich Environment." Journal of Applied Econometrics, 2019, 34, pp. 1050-72; https://doi.org/10.1002/jae.2725.

Lazarus, E.; Lewis, D.J.; Stock, J.H. and Watson, M.W. "HAR Inference: Recommendations for Practice." Journal of Business and Economic Statistics, 2018, 36, pp. 541-59; https://doi.org/10.1080/07350015.2018.1506926.

Mahoney, M.W. "Randomized Algorithms for Matrices and Data." Foundations and Trends in Machine Learning, 2011, 3, pp. 123-224; https://doi.org/10.1561/2200000035.

McCracken, M. and Ng, S. "FRED-MD: A Monthly Database for Macroeconomic Research." Journal of Business and Economic Statistics, 2016, 34, pp. 574-89; https://doi.org/10.1080/07350015.2015.1086655.

Medeiros, M.C.; Vasconcelos, G.; Veiga, A. and Zilberman, E. "Forecasting Inflation in a Data-Rich Environment: Benefits of Machine Learning Methods." Central Bank of Chile Working Paper, 2019.

Miranda-Agrippino, S. and Ricco G. "The Transmission of Monetary Policy Shocks." CFM Discussion Papers 1711, Centre for Macroeconomics, 2017; https://doi.org/10.2139/ssrn.2957644.

$\mathrm{Ng}$, S. and Perron, P. "Unit Root Tests in ARMA Models with Data Dependent Methods for the Selection of the Truncation Lag." Journal of the American Statistical Association, 1995, 90, pp. 268-81; https://doi.org/10.1080/01621459.1995.10476510.

$\mathrm{Ng}$, S. and Perron, P. "Lag Length Selection and the Construction of Unit Root Tests with Good Size and Power." Econometrica, 2001, 69, pp. 1519-54; https://doi.org/10.1111/1468-0262.00256.

Nicolò, G.D. and Lucchetta, M. "Forecasting Tail Risks." Journal of Applied Econometrics, 2016, 32, pp. 159-70; https://doi.org/10.1002/jae.2509.

Rossi, B. and Sekhposyan, T. "Macroeconomic Uncertainty Indices Based on Nowcast and Forecast Error Distributions." American Economic Review, 2015, 105, pp. 650-55; https://doi.org/10.1257/aer.p20151124.

Rousseeuw, P. and van Zomeren, B. “Unmasking Multivariate Outliers and Leverage Points." Journal of the American Statistical Association, 1990, 85, pp. 633-39; https://doi.org/10.1080/01621459.1990.10474920.

Schumacher, C. and Breitung, J. "Real-Time Forecasting of German GDP Based on a Large Factor Model with Monthly and Quarterly Data." International Journal of Forecasting, 2008, 24, pp. 386-98;

https://doi.org/10.1016/j.ijforecast.2008.03.008.

Schwert, G.W. "Tests for Unit Roots: A Monte Carlo Investigation." Journal of Business and Economic Statistics, 1989, 7, pp. 147-59; https://doi.org/10.1080/07350015.1989.10509723.

Sheppard, Kevin. "MFE Toolbox" (https://www.kevinsheppard.com/code/matlab/mfe-toolbox/) in MFE MATLAB Function Reference Financial Econometrics. Chap. 8.2.2. 2018; https://www.kevinsheppard.com/files/code/matlab/mfe-toolbox-documentation.pdf. 


\section{McCracken and Ng}

Smeekes, S. and Wijler, E. "Macroeconomic Forecasting Using Penalized Regression Methods." International Journal of Forecasting, 2018, 34, pp. 408-30; https://doi.org/10.1016/j.ijforecast.2018.01.001.

Stock, J.H. and Watson, M. "Forecasting Using Principal Components From a Large Number of Predictors." Journal of American Statistical Association, 2002, 97, pp. 1167-179; https://doi.org/10.1198/016214502388618960.

Stock, J.H. and Watson, M. "Why Has U.S. Inflation Become Harder to Forecast." Journal of Money, Credit, and Banking, 2007, 39, pp. 3-33; https://doi.org/10.1111/j.1538-4616.2007.00014.x.

Stock, J.H. and Watson, M. "Disentangling the Channels of the 2007-2009 Recession." Brookings Papers on Economic Activity, Spring 2012a, pp. 81-156; https://doi.org/10.1353/eca.2012.0005.

Stock, J.H. and Watson, M. "Generalized Shrinkage Methods for Forecasting Using Many Predictors." Journal of Business and Economic Statistics, 2012b, 30, pp. 481-93; https://doi.org/10.1080/07350015.2012.715956.

Stock, J.H. and Watson, M.. "Dynamic Factor Models, Factor-Augmented Vector Autoregressions, and Structural Vector Autoregressions in Macroeconomics," in J.B. Taylor and Harald Uhlig, eds, Handbook of Macroeconomics. Volume 2. Elsevier, 2016, pp. 415-526; https://doi.org/10.1016/bs.hesmac.2016.04.002. 